NBSIR 85-3242

\title{
A Report on the NBS-DOE May 1984 Workshop on Thermal Metering
}

George E. Mattingly

U.S. DEPARTMENT OF COMMERCE National Bureau of Standards Center for Chemical Engineering Chemical Process Metrology Division Gaithersburg, MD 20899

November 1985

Propared for:

$-Q C \longrightarrow$. Department of Energy

100 ice of Conservation

.456 shington, DC 20585

$85-3242$ 



\title{
A REPORT ON THE NBS-DOE MAY 9184 WORKSHOP ON THERMAL METERING
}

George E. Mattingly

\begin{abstract}
U.S. DEPARTMENT OF COMMERCE National Bureau of Standards Center for Chemical Engineering Chemical Process Metrology Division Gaithersburg, MD 20899
\end{abstract}

\section{November 1985}

Prepared for:

U.S. Department of Energy

Office of Conservation

Washington, DC 20585

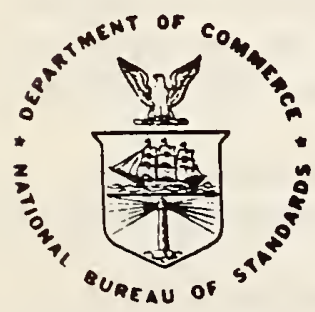

U.S. DEPARTMENT OF COMMERCE NATIONAL BUREAU OF STANDARDS 
George E. Mattingly

Chemical Process Me trology Division

Center for Chemical Engineering

National Bureau of Standards

Gaithersburg, MD 20899

\begin{abstract}
A workshop on thermal metering (i.e., the flow of steam or of hot or chilled water) was convened in Gaithersburg, MD, May 21-22, 1984 to discuss and prioritize measurement problems and research programs which could lead to improved energy conservation through the development and use of district heating and cooling systems. The workshop brought together 60 attendees whose expertise spanned a broad range of interests. Included were flowmeter manufacturers, meter users, standards personnel, academicians, and consultants. Attendees listed current problem areas and measurement needs in the rmal metering, discussed appropriate responses to these needs, and prioritized these according to their perceived potential for impacting thermal metering practice. Leading this list are:

- "paper" standards with special emphasis on "meter installation requi rements",

- research on two-phase flow and its measurement,

- two-phase flow technology transfer and information dissemination.
\end{abstract}

Key Words: district heating and cooling; energy conservation; flow; standards; thermal metering; two-phase flow.

Workshop Summary

This report is the summary of a two-day workshop held on hay 21-22, 1984 by the National Bureau of Standards (NBS) in Gaithersburg, MD. The workshop was sponsored by the Department of Energy's Office of Conservation and NBS. Its purpose was to discuss and prioritize the flowrate measurement problems, technical issues, research areas, which could enable energy conservation measures to be realized through the development and use of district heating and cooling (DHC) systems.

The workshop attendees were welcomed by Dr. Jarda J. Ulbrecht, Chief of the Chemical Process Metrology Division at NBS. Dr. Ulbrecht said:

"The National Bureau of Standards established a role for itself in developing fluid metering technology in the early $1900^{\prime} s$. In the area of orifice metering, NBS staff members Mr. Howard S. Bean and Dr. Edgar Buckingham together with others, and especially in collaboration with Professor Samuel $R$. Beitler of Ohio State supervised and/or consulted in orifice testing prograns over three decades from the $1920^{\prime} \mathrm{s}$. The result of this combination of testing programs, with others in the U.S. and abroad have produced the state-of-the-art in orifice metering as we know it - even today in the 1980 's. 
"Even today, calibration-testing programs continue to be conducted in the U.S. and in several countries in Europe to corroborate or to upgrade the levels of uncertainty associated with orifice metering. It is also beginning to be recognized that, in addition to this type of calibration testing and empirical approaches, other research tools - especially laser velocimetry and computer modeling techniques are available for studying fluid flows in orifice and other metering geometries.

"It is the purpose of this workshop to discuss the fluid flowrate issues that affect thermal metering, to suggest research programs to address these issues, and to prioritize them. The task seems clear, at least in principle; it is certainly most timely and appropriate; and I wish you every success in carrying out the goals of this workshop - I shall look forward to your results."

Mr. Jacob Kaminsky of the U.S. Department of Energy's Office of Conservation followed Dr. Ulbrecht's welcome with the following statement of purpose for the workshop:

"DOE's Office of Conservation is continuously looking for ways to conserve energy in the U.S. - both in the industrial and private sectors. One of the promising ways to do this can be through the advantageous economies of scale offered via District Heating and Cooling (DHC) Systems.

The economic feasibility of DHC systems is based upon the equitable custody transfer of energy between vendor and user. This transfer is carried out through an accounting chain based upon thermal measurements - i.e., the energy content in a fluid stream. Fluids range from wet and dry steam to heated and chilled water. Flowrates and pipeline sizes span a wide range. Measurement precision and accuracy is desired to be at or below the $1 \%$ level. The costs capital and operating - for the thermal measurement systems are to be kept at a reasonable level."

The purpose of this workshop is to: ( 1 ) determine the barriers - technical and otherwise - that currently prevent this level of thermal metering, (2) discuss these, (3) list them in priority order, and (4) suggest what should be done to improve matters.

To introduce the subject matter of the workshop, brief overviews will describe the state-of-the-art in thermal metering and the state-of-the-art in fluid metering research. These overviews were given by:

Mr. Norman R. Taylor

Executive Director

International District Heating Association (IDHA)

Washing ton, DC

Mr. Peter L. Turchi

Chairman, Fluid Meter Committee of IDHA, and ADCONS, Inc.

Bal timore, MD 


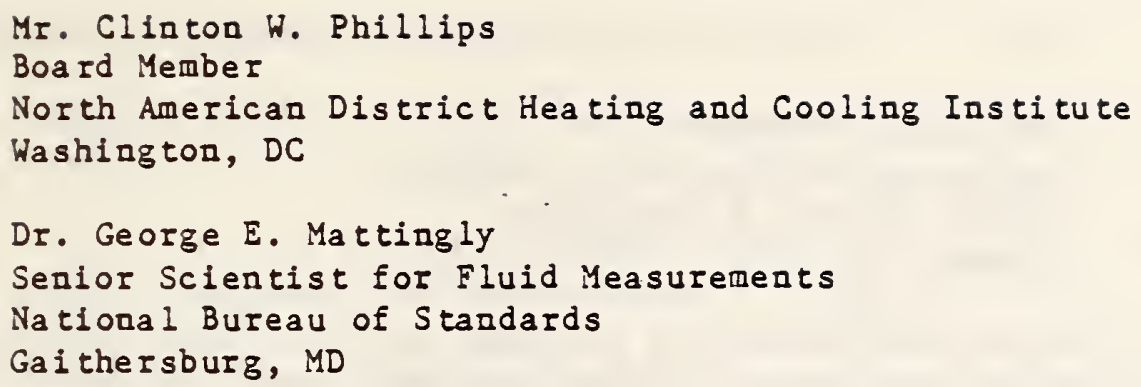

Task Group 1 - Installation Effects

\section{Professor William Durgin}

Department of Mechanical Engineering

Worcester Polytechnic Institute

Worcester, $\mathrm{MA}$

Task Group 2 - Measurement Techniques

Professor James Murdock

Department of Mechanical Engineering

Drexel University

Philadelphia, PA

Task Group 3 - New Technologies

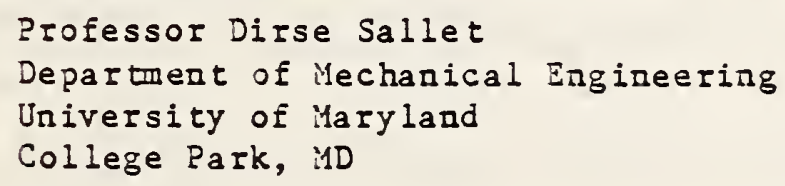

Task Group 4 - Standards and Calibration

Professor Thomas Araberg

Departnent of Mechanical Engineering

University of Colorado - Denver

and

Colorado Engineering Experiment Station, Inc. (CEESI)

Nunn, CO

Task Group 5 - Control Systems

Dr. James Hill

Chief, Building Equipment Division

Center for Building Technology

NBS - Gaithersburg, MD 
and

Mr. Narender Reddy

Energy and Environmental Systems

Argonne National Laboratory

Argonne, IL

Messrs. Kaminsky and Mattingly reviewed the fact that the letter sent inviting each of the attendees included a section which requested input regarding perceived:

- suggestions

- key issues

- items needing resolution

... that affect thermal metering and should receive attention during the workshop. This letter is included as Appendix No. 5.

The responses received are listed in Appendix No. 6. These responses are also provided to the respective Task Group Facilitators. Additionally, each attendee was provided a listing so that all participants have a set of the topics with which to begin their discussions in their respective areas.

The instructions to Task Group Facilitators were to add or subtract items from their listings as they deemed appropriate. Task groups were then asked to organize their topics, discuss these according to their pertinence for inproving cost-effective thermal metering, and describing what should be done about them.

As per the workshop schedule, see Appendix No. 7, the progress of each Task Group would be summarized by its facilitator for all the workshop attendees on the morning of the second day of the workshop. The discussion after each of the summary presentations will provide the opportunity for "cross-fertilization" anong the Task Groups.

A listing of the workshop attendees is given in Appendix 8 .

Task Group Summaries

The products from the Task Group deliberations are presented in summary form by the respective Facilitator as follows:

Task Group 1. Installation Effects -

Chairman: Professor W. W. Durgin

Department of Mechanical Engineering

Worcester Polytechnic Institute

Worcester, MA

Problem areas and issues will be identified, sub-divided into components, and the recommended responses given by the designated group or agency, in

parentheses. 
I. Measurement of Energy Transport in Wet Steam.

A. Identify Problem. (Trade association should respond to this issue).

B. Develop Measurement Methodology. (Response to this issue should be by DOE, academia, and the national labs).

C. Utilize Existing Test/Development Facilities, if possible. (Response to this issue should be by DOE, academia, and industry).

II. Reproducible Baseline Input Profiles. (Response to all these issues should be by DOE, academia, national labs, and NBS).

A. Fluid characteristics - Velocity (including swirl), temperature, and density.

B. Achievement in practice, flow conditioning.

III. Conduct Interlaboratory Fluid Metering Comparisons Programs. (Response should be by DOE, industry, and NBS).

A. Several laboratories are needed for cross-checks, these should use different methods for calibrating flowmeters.

IV. Write Thermal Meter Standards. (Response should be by professional societies and NBS).

A. Utilize existing standards where possible.

B. Develop new documents incorporating new technology as necessary.

V. Dissemination of Thermal Metering Technology and Information.

(Response should be by national labs and NBS).

A. Existing fluid and thermal metering codes and standards (trade associations).

B. Bibliography of pertinent texts, publications and reports (trade associations).

C. Short Courses on thermal measurement and related subjects should be generated, publicized, and presented on a regular basis.

D. Question and Answer Surveys regarding thermal measurements should be prepared, used, and results disseminated to inform all on problems and solutions (trade associations).

E. Thermal metering operating and maintenance guidelines (trade associations, vendors, and users).

F. Thermal metering installation guidelines (trade associations, vendors, and users). 
G. Publication of thermal measurement case studies (Trade Associations).

Task Group 2 - Thermal Metering

Chairman: Professor James Murdock

Department of Mechanical Engineering

Drexel University

Philadelphia, PA

Problem areas and issues will be identified, described briefly, and the recommended responses given by the designated group or agency, in parentheses.

I. Standards for thermal metering, including related system design considerations. (Response to this issue should be by such professional societies as ASME and ASTM with trade association cooperation.)

II. Independent laboratories should be established with capabilities for calibrating thermal meters (including steam). These laboratories should have their measurement processes traceable to NBS. (Response to this issue should be by DOE with "seed funding" and by industry funding with the steam trap industry).

III. Research in thermal metering of two-phase flows. (Response to this issue should be by DOE with "seed funding" by NBS, by academia, and by industry.

Task Group 3 - New Technologies

Chairman: Professor Dirse Sallet

Department of Mechanical Engineering

University of Maryland

College Park, MD

Problem areas and issues are identified, briefly described, and the recommended response given by the designated group or agency, in parentheses.

I. Basic research is needed to characterize the regimes of two-phase pipe flow. (Response to this issue should be initiated by DOE, academia, indus try, and NBS).

II. Improve the capability of "Standard Metering Techniques" to make thermal metering cost effective. Measurements in one and two phase thermal streams. (Response should be by DOE and industry). By "Standard Metering Techniques" is meant turbine, vortex shedding, and differential pressure type devices, etc.

III. Determine "Prospective New Techniques" and schemes for thermal metering and assess these according to their cost effectiveness for making the desired levels of thermal measurement. (Trade association support). By "Prospective New Techniques" is meant such techniques as magnetic resonance, pulsed neutron activation, ultrasonic, angular momentum, etc. 


\section{Task Group 4 - Standards and Traceability}

Chairman: Professor Thomas Arnberg

Department of Mechanical Engineering

University of Colorado - Denver

and

Colorado Engineering Experiment Station, Inc. (CEESI)

Nunn, CO

Problem areas and issues are identified, briefly described, and the recomended responses given by the designated group or agency, in parentheses.

A. "Paper" Products:

I. Thermal metering performance standards. (Response should be by trade association). Thermal metering testing standards.

(Response should be by professional societies).

II. Application and installation manual. (Response should be by trade associations).

III. "In-situ" testing technique manual. (Response should be by professional society).

IV. Certification program - manual. (Response should be by trade association).

B. "Hardware" Products:

V. Manufacturer's testing. (Response by industry).

VI. Certification - commercial testing laboratory. (Response should be by industry).

VII. "In-situ" testing device development. (Response should be by NBS and academia.

Task Group 5-Control Systems

Co-Chairmen: Dr. J. E. Hill

Center for Building Technology

NBS - Gaithersburg, MD

and

Mr. Na render Reddy

Energy and Environmental Systems

Argonne National Laboratory

Argonne, IL

A. Problem Areas:

1. Current district heating systers are being designed with sinplified control algorithms that result in suboptimum efficiency of the plant and no load management. 
2. Current district heating control systems are not operating as intended.

3. Utilities refuse to purchase excess electricity from total energy plants that feed district heating systems.

B. Proposed Research:

Response to the above-numbered problem areas:

1. Develop and verify algorithms for advanced district heating and cooling control and load management.

2. None - Industry should follow-up to see that existing systems are checked out and operated properly; operators are trained properly.

3. ?

C. Other Issues:

1. The problem of building submetering and control systems (e.g. distribution of steam to apartments from a central source) are is similar to the problems confronting those attempting to build DH (district heating) systems.

2. The link between metering and instrumentation and control system is the same regardless of whether current control or advanced control algorithms are used.

D. Effect of Proposed Research:

1. Increased plant efficiency.

2. Improved load management.

3. Enhanced safety and reliability.

4. Lower operating costs.

5. Automated data acquisition for metering and billing. 
After presentation of Task Group deliberations by the respective Facilitator, the results of the individual groups were surveyed to determine identical or similar issues. This effort produced the following listing of prioritized issues that were approved by ballot of the attendees.

1. Thermal metering standards with special emphasis on installation requirements.

2. Certification techniques (calibration facilities) adequa te to and including the verification needed to assure the needed levels of measurement.

3. Two-phase flow measurement research to assess and develop accurate, low cost techniques.

4. Devices to perform "in-situ" checks on thermal measurements.

5. Generic flow sensor development programs.

6. Dissemination systems for thermal measurement information and technology transfer.

The above issues might be regrouped under three headings:

I. Standards - installation requirements, operation techniques, levels of performance, etc.

II. Calibration Facilities - laboratory, "in-situ" proving, traceability, etc.

III. Research - flow and related sensor development for accurate, low-cost the mal measurements.

This order of priority (I, II, III) reflects the consensus researched in the final session of the workshop. 

Metering Issues in District Heating and Cooling

\author{
N. R. Taylor \\ Executive Director \\ International District Heating and Cooling Association (IDHCA) \\ Washington, D.C.
}

The sale of any commodity to the consumer generally has some form of regulation as to quantity or quality. Scales in markets must be certified, gasoline pump meters are checked to assure accuracy, electrical materials bear labels of approval, as do most food products. The thermal heating/cooling business is no different and there exists well defined rules and regulations for the transfer of these products to the consumer in exchange for dollars. Most often such standards are established by state regulatory offices and may be referred to as "PUC Regulations".

Examining a cross section of such regulations prepared in general, for steam distribution companies, we find some basics that give us a foundation for our discussion of thermal metering. Some of the essentials are:

Meter. The word "meter", when used in these regulations without other qualification, shall be construed to mean any meter or device which is installed by the utility for measuring the quantity of service rendered to a customer.

Meter Accuracy. All meters shall be adjusted before installation so as to register with an error of not more than $2 \%$, and this adjustment shall be maintained as nearly as possible in meters which are in service. If any meter in service is found to register with an error of more than $3 \%$ when subjected to tests, as outlined below, it shall be deemed inaccurate.

Meter Tests. There are many types of tests that can be applied to meters in a variety of situations both in the field, in the shops of the supplier, at the facilities of the regulatory body, or at an independent laboratory. Some "test" definitions are:

\author{
Laboratory Test \\ Service Test \\ Installation Test \\ Periodic Test \\ Request Test \\ Referee Test
}

\author{
Office Test \\ Repair Test \\ Inspection \\ Check Test \\ Special Test
}

Facilities for Testing. Each utility, unless specifically excused by the Commission, provides such laboratory meter testing equipment and facilities as may be necessary to make the tests required of it by these rules or any orders of the commission. The apparatus and equipment so provided shall be subject to the approval of the commission, and it shall be available at all times for inspection or used by any member or authorized representative of the commission. That various gauges, scales, thermometers, etc., used in make test, shall be calibrated as frequently as necessary for maintenance of accuracy. 
The types of meters are recognized by most regulations and specific tests are designa ted:

Condensation Meters. Condensation meters shall be tested by passing a known quantity of water through the meter. In the case of rotating type meters, one test shall be made at not more than $25 \%$ of rated capacity, using in no case less than 20 pounds of water, and one test at not less than $75 \%$ of capacity. The arithmetical average of the accuracies at these test points shall be deemed the accuracy of the meter. However, the variation in accuracy at different ratings shall not exceed $3 \%$.

Flow Meters. Flow meter shall be tested on the consumer's premises by careful measurement of orifice size, static pressure and pressure differential. Check of differential pressure at any point shall be made with increasing and decreasing flows, using the average as the calibration pressure for that flow point. In the case of the graphic or chart typemeters, the chart record shall be checked against the static pressure and pressure differential as determined by test. Such checks shall be made at not less than three points, as follows:

1. At approximately $25 \%$ of chart range, with a permissible accuracy tolerance of $\pm 3 \%$

2. At a point not less than $50 \%$ nor more than $75 \%$ of chart range, with a permissible accuracy tolerance of $\pm 2 \%$.

3. At approximately full scale, with a penissible accuracy of $\pm 2 \%$.

Other Meters. Any other type meter shall be tested in accordance with the manufacturer's recommendations and as approved by the commission and shall insure accuracy commensurate with that of flow meters.

Most regulations also specify conditions by which the supplier can furnish data to a regulatory agency as to the quantity and quality of the product.

Station and Consumption Records. Each utility shall maintain such instruments and meters at each generating station as may be necessary to obtain a daily record of the load and a monthly record of the output and to show continuously the character of service being rendered therefrom.

These rules, together with the standard operating procedure of the supplier provide the background for reasonable cost accounting between the customer and the company. How much money the company pays for the meter, what type is purchased, where it is installed and how it is utilized, is generally left to the company. The same capacity steam meter may cost $\$ 200$ or $\$ 5000$, it is a matter of conditions of supply and utilization.

Metering any product is largely a decision making process. 


\author{
Mr. Peter L. Turchi \\ Chairman, IDHA Committee on Fluid Metering \\ and \\ ADCONS, Inc. \\ Baltimore, MD
}

As representatives from the thermal metering community, we are here to discuss themal measurement and its meaning to the customer and the non-utility selling agency. It is quite evident that anytime that you have a billing adjustment that is estimated the feeling is buyer beware. On the other hand, if we can measure with confidence over the entire range with an accepted accuracy to both parties, then any loss of measurement is accepted by the seller as a pro-rated sys tem loss.

It becomes very evident that any meter based on "range accuracy" rather than "reading accuracy" can be in greater error at the lower end of the scale, depending upon rangeability of the instrument. That can be a detriment to either the customer or the seller. We do not believe that any customer would not be willing to pay for a utility that he feels has an accurate accountability.

Standards for metering, especially steam are either based on water or air. As a note, when we measure BTU's for either hot or chilled water systems, we measure the differential temperature of the fluid and in most cases, flow on the inlet side. Makeup is rarely accounted for. We believe there is a fallacy in $s$ team measurement systems in that a total amount of steam sent to a customer is billed and where there is a condensate return system, that is not metered. Consequently, the customer is paying for $100 \%$ of the energy transported to him. On the other hand, where the condensate is measured, the seller is not at the mercy of any trap losses and other leaks in the customer's system.

It becomes obvious that in protection of the seller and customer, total energy usage can best be measured by the meter on the inlet and the meter on the outlet of the customer system. It then behooves both parties to maintain their individual systems. In the case of the customer, if he doesn't it results in a higher billing. In the case of the seller, it now becomes the responsibility of a governing body or public service utility to govern the percentage of losses that can be accounted or added to the customer's bill.

What is our part? Our part is to look for those areas that need development in order to achieve the best metering system possible which not only includes the meter, but also piping, controls and whatever else we should develop at this meeting. Over the years, I have learned that there is no stopping the learning process and each of us can learn from each other. With that in mind, I feel certain that collectively we will all come out of these next two days with far more questions that need to be answered than we have today.

Thank you. 



\author{
Mr. C. W. Phillips \\ Technical Director \\ North American District Heating and Cooling Institute (NADHCI) \\ Washing ton, D.C.
}

Good morning. I am Clint Phillips - Member of the Board of the North American District Heating and Cooling Institute, and the person responsible to pull together NADHCI's metering standards and related R\&D efforts.

We are all here, hopefully, because we want to help enhance the expanded role of DHC in America's cities, and recognize the key role of metering in that regard.

Our Executive Director, Dick Eckfield, had hoped to be here with us this morning, in fact was to have made this opening statement. He knows many of you, and in addition to the substance covered at these meetings, because they also provide a good opportunity to make new acquaintances and renew acquaintenances, he is sorry to miss this opportunity.

However, there is another issue that is also key to DHC development, and that is the creation of favorable tax incentives for DHC development - and the key person here is House Ways and Means Chairman Dan Rostenkowsy.

To organize the educational briefings for Chairman Rostenkowsky it has been necessary for us to work with the key-opinion leaders in Chicago to share with them our vision for DHC. That effort has culminated in a half-day seminar for the key city officials and the major Chicago area developers. That meeting, which Dick Eckfield is keynoting, is today in Chicago. Thus, he is there - and I am pleased to be with you here today - to add our support for the purposes of this meeting. I want to take a couple of minutes to tell you why we at NADHCI place such importance on metering.

1. Accurate metering will be a key ingredient in the development of the DHC market in American cities.

- We expect to see much of the new DHC development to be sponsored by private entrepreneurs, or public and quasi-public institutions (such as universities) who will embrace system expansion and metering for entrepreneurial reasons.

In all instances, the system developer will need to recover all the revenue possible. Thus, accurate metering for billing purposes is essential.

In a highly competitive market where economics of the cost of energy will determine new customer hook-ups, there will be little room for error in the metering, and in a cost-conscious environment there is little room for 'gilding' of the individual meters.

Thus, in what may appear to be a contradiction - we need meters that are the most accurate possible - which must be installed at the lowest possible cost. 
2. We know that strong reliable standards - both performance and testing are important if we are to be able to build accurate yet inexpensive metering devices.

- We have spoken to several of you about the perceived need to develop such standards for the measurement of both the flow and the temperature differential - thermal measurement - for hot water, chilled water, and steam meters. We have contacted ANSI in regard to the development of such standards. They appear to be needed. We have been in contact with ASHRAE regarding our collaboration in the development of such standards. One of the things we will be looking for, particularly from our members, is feedback from this meeting on what the scope of such standard(s) should be.

3. One last item of more immediate interest is the effort NADHCI is putting together with the public housing administration in HUD regarding master metering and tenant sub-metering of public housing units.

- A few months ago, as some of you know, we began to work out the scope of a public housing metering demonstration effort. I participated in the first meeting - which lasted all morning - with the Assistant Secretary for Public Housing (Warren Lindquist - March 23).

I can tell you definitely there is interest in our proposal - and we at NADHCI place a special importance on this segment of the total industry ... as a major key to DHC expansion in American cities ... and improved metering is necessary for that effort to succeed.

We were pleased to work with the development of this meeting today. We look forward to the results. 
Improved Thermal Metering: New Research

Tools and New Opportunities

G. E. Mattingly

Senior Scientist for Fluid Measurements

Chemical Process Metrology Division

Center for Chemical Engineering

National Bureau of Standards

Gaithersburg, MD 20899

Summa ry

To realize the potential energy conservation benefits offered by District Heating and Cooling (DHC) schemes that are based on equitable custody transfer of thermal energy, cost-effective measurement capabilities are essential. The required measurement capabilities to achieve the $2 \%$ accuracy levels described previously by Mr. Norman $R$. Taylor are very difficult to achieve in the wide range of metering conditions that confront (and confound!) users. For example, the installation specifications called for by meter vendors to achieve stated levels of meter performance can not always be met in practical situations. In many cases, meters are installed too near elbows, valves, and piping reducers or enlargements. Few, if any, of these installation situations have been calibrated and, as a result, meter performance has been found to deviate widely from predictions.

To remedy this situation there are available now new research tools for conducting metering research. These differ radically from the methods used in the past i.e., calibration testing. The new tools - laser Doppler velocimetry (LDV), computer modeling, and high speed flow visualization enable a new strategy in metering studies - determining the flow field into and inside a metering geometry, understanding this flow, and arranging the operation of the meter to achieve and assure the desired level of performance.

These research tools and this strategy enable significant improvements in thermal metering to be made in efficiently arranged and sponsored projects. Results would be disseminated to meter vendors and users alike. Concurrently, results would be incorporated into metering standards and specifications. The ultimate result would be the attainment of metering performance that is adequate and satisfactory to both the buyers and sellers of energy in DHC systems.

\section{INTRODUCTION}

To attain the potential energy conservation benefits from District Heating and Cooling (DHC) schemes that involve custody transfer of the rmal energy, cost-effective measurement capabilities are essential. In fact, the acceptance of such concepts, the implementation and use of such systems hinges critically on the accuracy, precision, and costs of both capital and operating of the instrumentation necessary to make these thermal measurement systems economically viable. 
Thermal Metering Requirements. Thermal measurements systems are needed over the widely ranging conditions of operations described above by Taylor and Turchi. Throughout these ranges of conditions, fluid metering research programs will be needed to improve existing methods of the rmal measurement and to evaluate the feasibility of new techniques which show potential for these tasks. In what follows, emphasis will be placed upon the measurement of fluid volumetric flowrate; the detemination of temperature, pressure, or the energy content of the fluid stream will be considered an auxiliary one. Emphasis will also be placed upon the newly available research tools and how these can produce more detailed understanding of fluid meter performance than could be attained using the "research" methods of the past.

Historical Perspective. In the past, fluid metering research was carried out by calibration techniques - using discharge coefficients and meter factors and the variations of these as performance indicators. Upstream piping configurations, meter variations, fluids, and flowrates were arranged and the installed meter was calibrated. Individually, the parameters were varied and calibration was repeated until a satisfactory range of conditions was covered by the calibrations. The resulting data was analyzed to determine the nature and amount of variation that occurred in the discharge coefficient or meter factor.

Calibration Benefits. This approach had considerable practical value provided the conditions of the calibrations precisely duplicated a meter installation, and provided the accuracy and precision desired of the meter did not exceed that obtained in the calibration. Additionally, in the past the fluid research tools needed to go beyond this "calibration - produced" understanding of meter performance did not exist. Consequently, it was not possible to make detailed measurements of flow velocity into or through the meter geometry; it was not possible to understand the instantaneous distributions of fluid pressure or temperature in the meter's flow field. As a result, when meter installation conditions differed from those of a known calibration, or when changes in meter conditions - such as orifice edge sharpness, pipe roughness, or secondary instruments i.e., manometry or transducer systems occurred, it became uncertain how to predict the nature and amount of change in meter performance. Similarly, when the need arose to reduce metering uncertainty, little guidance was given via the calibration data as to which of the many variables controlling meter performance should be changed (and how much) so as to achieve the desired improvement. Therefore, it is concluded that an improved level of understanding be established so that hierarchy of the factors that affect meter performance are understood. Using this understanding, meter standards for installations can be specified and operating procedures laid out so that desired performance can be attained. To achieve this understanding will require significant metering research.

\section{FLUID METERING RESEARCH}

The purpose and strategy for fluid metering research have several components, as shown in Table 1: 
Table 1. Fluid Me tering Research

1. Purpose:
A. Improve existing me tering techniques
B. Assess and establish new metering technologies

\section{Stra tegy:}
A. Focus fluid mechanical expertise on the salient phenomena governing meter performance
B. Apply new fluid dynamical research tools to meter flows

The details as to how these are achieved are to result from the discussions of this workshop.

Thermal Metering. A number of flow measurement devices offer potential for the rmal metering. These can be subdivided as to their potential for making volumetric or mass flow rate measurements, as shown in Table 2. Rather than address each of these devices and describe or infer how its performance can deviate from "the ideal", it will be sufficient to select the prevalently used orifice meter and use it as a generic example. The essential point to be made is that before the performance of any metering device is optimized, the factors that significantly affect it must be thoroughly understood.

Ideal Orifice Performance. The time-averaged, ideal orifice flow field, shown in Figure l, has been the focal point of many studies and a recent workshop organized to determine the fundamental research issues in orifice technology, see (1).* References (2-22) describe a range of orifice studies and some of the results obtained from them. These have shown conclusively that the orifice flow field is altered by a number of effects. For example, the ideal flow pattern can be perturbed by fluid dynamic instabilities, coherent structures, turbulence, pulsations, etc. These sources of deviations affect the flow and pressure distributions shown in Figure 1, causing them to deviate from those assumed in deriving the metering equations in use. This affects the accuracies and performance of the orifice meter. Performance deviation due to individual effects varies in magnitude and when multiple effects are present, the combined effect can be diminished or enhanced. Because instabilities and coherent structures can develop naturally in the orifice jet and because the turbulence distributions in the flow field are inherent to the flow in this geometry, we shall confine our attention to these aspects.

Pulsation effects as transmitted from specific sources, such as valves, pumps, and compressors, etc. are dependent on the characteristics of these sources. For this reason, these will not be dealt with in the discussion that follows. References $(23-27)$ present current descriptions of the effects of pulsations on orifice meters and on other differential pressure type meters.

*Integers in parentheses refer to references given below. 
Table 2. Flow Measurement Devices

I. Volumetric Flow Rate

1. Differential Pressure Type
a) Orifice
b) Nozzle
c) Venturi
d) Pitot
e) Laminar

2. Turbine
a) Full bore
b) Insertion
c) Paddle

3. Vortex
a) Shedding-type
b) Swirl meter

4. Elec tr omagne tic

5. Acoustic

6. Positive Displacement

7. Force Type
a) TaIget
b) Variable area

II. Mass Flow Rate

1. Angular momentum

2. Coriolis

3. Acoustic

4. Therma 1 
Because the fluid inertial effects in most pipelines far exceed viscous effects, orifice flows are predominantly turbulent. As a result, the pressure distributions along the pipewalls have a corresponding randomly varying component which can significantly affect the level of uncertainty and the accuracy of flow measurements with orifice meters.

For incompressible, one-dimensional, steady flow, the conservation of mass and energy relationships can be used to produce the theoretical mass or volumetric flowrate that will occur through the orifice construction from a high pressure upstream to a lower pressure downstream. The actual flow rate can be computed using a discharge coefficient, $C_{D}$ and the theoretical flowrate as follows:

$$
Q=\frac{{ }_{d} C_{d}}{\sqrt{1-\beta^{4}}} \frac{\sqrt{2 \Delta P}}{\rho} .
$$

where, in compatible units, $Q$ is the volumetric flowrate, $A_{d}$ is the orifice hole area, $\beta$ is the orifice hole to pipe diameter ratio, $\Delta P$ is the pressure difference, and $\rho$ is the fluid density. The discharge coefficient is dependent on the orifice geometry, a sequence of dimensionless flow parameters, and the specific installation. The deviation of the discharge coefficient from unity can be considered to be a measure of the deviation of actual conditions from the assumptions involved in applying the above described conservation equations to orifice flow.

Perturbations on Ideal Orifice Performance. Deviations from ideal conditions. can result from anomalies in pipe geometry, plate geometry, and inlet flow. Examples of each of these are given in Table 3, see also Figs. 2-3. Piping configurations can produce perturbations on the perfomance of meters placed too closely to elbows, pipe diameter changes, or partially opened valves, see Figs. $4(a)$ and (b). As well, these results form the basis for recommending meter installations where these perturbing influences have been diffused either naturally or through flow conditioning, see (28-35).

Flow Conditioning. Flow conditioning philosophies vary as do the associated devices. A detailed review is given in (36). A prevalent flow conditioning philosophy is to remove artificially those flow anomalies which affect orifice meter performance.

Tube bundle flow straighteners, which consist of large numbers of small tubes are quite prevalent. These bundles, which are several pipe diameters in length, are placed upstream of orifice meters so that, through "wave-guiding" action, they reduce secondary motions such as sketched in Figs. $4(a)$ or $4(b)$.

The tube bundle's effectiveness in reducing swirl reduces the need for long lengths of straight pipe. Similar to tube bundle straighteners are the "slat-type" and the "Etoile" straighteners. These use wave-guiding action produced by small square or triangle passages produced by assemblies of flat plates. 


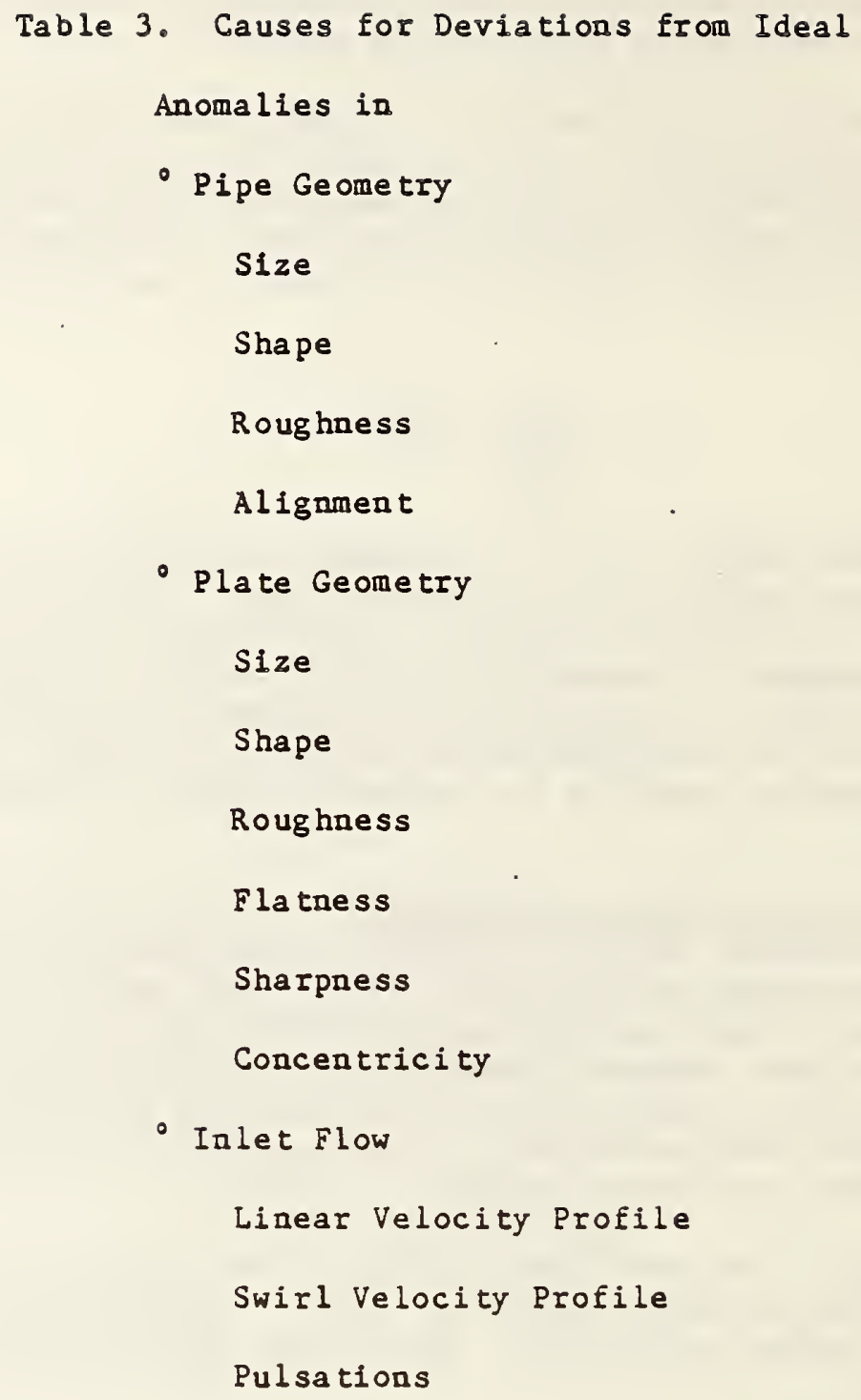


Sprenkle* flow conditioners consist of multiple discs, usually three, having large numbers of small holes drilled through them. These discs are supported across the cross-sectional area of a pipe flow to produce highly turbulent wakes. These wakes are designed to mix the fluid kinetic energy so that swirl is diffused and the streamwise component of the velocity profile closely resembles a "fully developed" pipe flow profile - i.e., that which would evolve natually via very long lengths of straight pipe.

A Zanker-type flow conditioner is basically a combination of a single Sprenkle disc followed by a "slat-type" straightener. It is designed to construct a "fully developed" pipe flow distribution through selected disc hole sizings aligned with each channel of the straightener, see (37). A design somewhat similar to the Zanker type device is beconing known as the Mitsubishi flow conditioner ( 38 ).

Using computer modeling techniques to calculate the flow fields through reasonably simple flow conditioning geometries, NBS staff have produced a configuration that shows good conditioning potential. This conditioner turns the pipe flow through four $90^{\circ}$ turns and includes passing the flow through a cylindrical surface containing small holes. The resulting tortuosity produces very repeatable flow profiles in only a few diameters downstream of this device regardless of the anomalies in the distribution of the streamwise flow velocity entering the device, (39). This approach uses the second conditioning philosophy of attempting to produce an extremely repeatable flow profile regardless of that which enters the conditioner. In this manner, once the flow conditioner and meter are calibrated (or otherwise characterized) as a unit, the combination can be expected to produce extremely reliable measurements.

Thus, our short review shows that orifice discharge coefficients can be affected by a number of factors. These can interact with one another to produce combined effects which, in turn, can either enhance or offset their individual effects on the discharge coefficient. Assessing the significance of these effects individually is very difficult - especially if only calibration and testing procedures are used. Assessing their significance in combination is virtually impossible in light of the extremely large number of separate tests then required. Since these effects readily interact with one another through the fluid medium, their effects on prevailing discharge coefficients should be significant.

As mentioned above, testing programs have been extensively used to characterize the perfomance of meters. This is understandable in light of the fact that the capabilities available in fluid research for observing the fundamental fluid phenomena inside flow meters were severely limited. It is our purpose here to show that this is not the case today and that new research opportunities are now available to measure, study and understand these phenomena and their effects on meter performance on a fundamental level.

New Research Opportunities. To understand the basic fluid phenomena that control meter performance, it will be necesary to understand how the sources of the various performance perturbations affect the operation of the meter. To do this, new techniques will be needed, especially the experimental and computational ones that are now available for these studies.

*Device patented by R. E. Sprenkle at the Bailey Meter Co., Wycliffe, Ohio. 
Experimental Techniques. Some of the experimental techniques intrude into the flow field to obtain desired measurement; others do not. Table 4 lists a number of each type.

\section{It is pertinent here to describe these further.}

Pitot tubes, shown schematically in Figure 5 have the capabilities of measuring the streamise component of the mean flow velocity distributions, see (40). Care should be taken to measure the fluid velocity without disturbing it. For example, a pitot tube inserted downstream of the orifice plate could disrupt the normal dynamics which occur in the eddy system which resides there.

Anemometry techniques which use heat transfer from small elements - hot wires for gas flows and hot films for conducting liquids like water - can measure one or more components of the velocity and are capable of very high frequency response, see $(40,23)$. As such, these can be used to measure flow instabilities, coherent structures, and turbulence. As with pitot tubes, however, care must be used to minimize the intrusive nature of the sensors involved. Figure 6 sketches the way in which the technique could be used to measure streamise velocity components.

Many visualization techniques have been developed in recent years. Among these, the smoke wire visualization technique is well-suited for use in orifice geometries. Figure 7 shows a configuration that can produce photos of the fluid dynamics in the orifice jet where instabilities and coherent structures can occur. Figure 8 shows typical results using this smoke wire technique. Note the vortices generated at the edge of the orifice jet. The cyclic pulsations produced by these can be transmitted directly to the downstream pressure tap:

Dye injection techniques have been used in orifice meter research (23). Figure 9 shows several arrangements that can be used to picture the fluid dynamics upstream or downstream of the plate.

The hydrogen bubble flow visualization technique uses the electrolysis of water to produce small hydrogen bubbles that, with proper lighting, can be viewed with the naked eye or photographed ( 41 ). These small bubbles have a buoyancy to drag ratio that is proportional to the bubble diameter. For sufficiently small bubbles, buoyancy becomes negligible making them ideal tracers to portray fluid motions. By placing the cathode terminal in the form of a thin wire supported where bubble injection is desired and the anode terminal in an inconspicuous location in the flow, visible bubbles can be generated at the cathode using pulsed or d-c excitation. Figure 10 sketches both the electrode arrangements to generate bubbles in a diametral plane as well as the bubble patterns that can be produced.

Laser Doppler velocimetry (LDV) is an ideal technique for use in orifice research, see (42). Figure 11 sketches an arrangement of components to measure the streamwise component of the fluid velocity. It is capable of measuring in a non-intrusive manner, one or more components of the fluid velocity in a field inside the orifice geometry. Because the technique is based on light scattering phenomena, it is capable of very high frequency response. In addition, by using multiple sensing schemes, this technique makes it possible to perforn the correlation measurements needed to describe turbulent flow fields properly. LDV is an ideal experimental research tool with which to measure orifice flows. 
Table 4. Experimental Techniques for Orifice Flow

A. Intrusive

1. Pitot Tubes

2. Anemome try

- Hot Wire

- Hot Film

3. Visualization

- Smoke Wire

- Electrolysis

B. Non-Intrusive

1. Visualization

- Dye Injection

2. Optical

- Interferometry

3. Laser Doppler Velocimetry 
Figure 12 presents typical results from some preliminary velocity traverses measured at NBS.

In compressible orifice flow where fluid density variations occur, interferometry is capable of producing, in an non-intrusive manner, both qualitative and quantitative records for orifice flow. Figure 12 sketches an arrangement through which interferometry can be used to give the density field in an orifice flow ( 40$)$.

These techniques offer tremendous potential for experimentally measuring and understanding metering flows. Additionally, there are computational techniques which can be applied to studying metering flows.

Computational Techniques. Computational approaches to understanding orifice. flow offer tremendous potential because they enable one factor to be changed at a time while holding others fixed and generating the entire metering flow field. In fact, these computations offer the possibility of making such changes and producing the associated flow quite rapidly. In this way, the influence of the various factors on the flow field can be individually assessed in a time period which is short in comparison to the time required to conduct the analogous experiment. Examples of computational techniques can be found in (43-47). When coupled with experimental investigations that are essential to both guide and verify computational procedures and results, this dual approach offers the maximum potential for understanding orifice flow. A description of this powerful research tool is given by Professor K. Ghia and U. Ghia in (1).

Techniques such as those discussed briefly above, when used in conjunction with corresponding computer modeling efforts, offer immense potential for the attainent of a fundamental understanding of orifice flow. Experimental results, especially those obtained via non-intrusive measurement techniques such as LDV, now enable quantitative descriptions of orifice flow phenomena that were not possible previously. These descriptions will have the three-fold benefit of: 1 - increasing the current knowledge of orifice phenomena, 2 - providing essential input to the initiation of computer modeling efforts designed to compute orifice flow, and 3 - validating the predictions of the computer model. Once the two approaches (i.e., fundamental flow experinents and computer modeling) are underway, the interactive collaborative efforts are expected to be highly productive in establishing a credible understanding of the factors affecting orifice performance. This understanding, implemented in practice both nationally and internationally via codes and standards, should improve orifice measurements significantly.

CONCLUSIONS

We have attempted to show that new research efforts are now needed to produce an understanding of the fundamental fluid dynamic phenomena that control the performance of thermal metering devices. This understanding and how those phenomena controlling meter performance are affected by the parameters involved in metering practice will lead to improved standards, improved installations, as well as improvements in fluid measurement technology. This, in turn should produce the improved levels of measurement accuracy currently demanded by industry. The new experimental research tools needed for these efforts exist and are available. These efforts, in conjunction wi th collaborative computational counterparts, offer maximal potential to establish the 
understanding needed. When a collaborative testing program is added, to confirm practical metering performance the way to dramatically improve metering practice becomes clear. All that is needed is the commitment by science and industry to pursue the task at hand and to reap the resulting scientific and industrial rewards.

\section{References}

1. Mattingly, G.E., Spencer, E.A., and Klein, M. - Workshop on Fundamental Research Issues in Orifice Metering; Gas Research Inst. Rept. 84-0190, Oct. 1984. 156 p.

2. Rouse, H. and Abul-Fetouh, A., "Characteristics of Irrotational Flow through Axially Symmetric Orifices", Journ. of Appl. Mechs., Trans. ASME, Vol. 17, No. 4, 1950, pp. 421-426.

3. Chen, Y.L., "Inviscid Rotational Axisymmetric Flow through a Sharp Edged Concentric Orifice in a Circular Pipe", PhD. dissertation, Univ. of Rhode Is land, Kingston, RI, 1973.

4. Teyssandier, R.G., "Internal Separated Flows-Expansions, Nozzles, and Orifices", PhD. dissertation, Univ. of Rhode Island, 1973.

5. Teyssandier, R.G. and Wilson, M.P., "An Analysis of Flow through Sudden Enlargements in Pipes", Journal of Fluid Mechanics, Vol. 64, Part I, 1974, pp. 85-95.

6. Wilson, M.P. and Teyssandier, R.G., "The Paradox of the Vena Contracta," Journal of Fluids Engr., Trans. ASME, Sept. 1975, pp. 366-371.

7. Mills, R.D., "Numerical Solutions of Viscous Flow through a Pipe Orifice at Low Reynolds Numbers", Journal of Mech. Engr. Sci., 10, No. 2, 1968, pp. $133-140$.

8. Greenspan, D., "Numerical Studies of Viscous Incompressible Flow through an Orifice for Arbitrary Reynolds Number", Int'l. Journal for Numerical Methods in Engineering, 6, 1973, pp. 489-496.

9. Dowdell, R.B. and Wilson, M.P., "Status of the Analysis of Flow through Concentric Square Edged Orifices", ASME Paper 75 WA/FM-4, Houston, TX, 1975.

10. Dyban, Y.P. and Epik, E.Y., "Effects of Turbulence on Calculating Heat Transfer Downstream of an Orifice in a Tube", Heat Transfer, Soviet Research, Vol. 2, No. 1, Jan. 1970, pp. 11-16.

11. Chaturvedi, M.C., "Flow Characteristics of Axisymetric Expansions", Journal of Hydraulics Div., ASCE, May 1963, pp. 61-92.

12. Lipstein, N.J., "Low Velocity, Sudden Expansion Pipe Flow", ASHRAE Journal, Vol. 4, 1962, pp. 43-47. 
13. Bourque, C. and Newman, B. G., "Reattachment of a Two-Dimensional Incompressible Jet to an Adjacent Flat Plate", The Aero Quarterly, Vol. XI, Aug. 1960, pp. 201-232.

14. Ackeret, J., "Aspects of Internal Flow", Fluid Mechanics of Internal Flow, G. Sovrin, ed., Elsevier, Amsterdam, 1967, pp. 1-26.

15. Jeppson, P. W., "Inverse Formulation and Finite Difference Solution for Flow from a Circular Orifice", J.Fluid Mech., Vol. 40, part 1, 1970, pp. 215-223.

16. Hunt, B. W., "Numerical Solution of an Integral Equation for Flow from a Circular Orifice", J.Fluid Mech., Vol. 31, 1968, pp. 361-77.

17. Ghazi, H. S., "A Pressure Index for Predicting the Effect of the Flow Profiles on Orifice Meter Performance", Paper No. 65-WA/FM-3, Journal of Basic Engr., Trans. ASME.

18. Stearns, R. F., et al., "Flow Measurement with Orifice Meters", D. Var Nostrand Co., 1951 .

19. Scott, R.W.W., "Developments in Flow Measurement - I", Applied Science Publishing, London, 1982.

20. Miller, R. W., "Flow Measurement Engineering Handbook", McGraw-Hill, New York, 1983.

21. Brennan, J., et al., "An Evaluation of Selected Cryogenic Flowmeters", NBS TN $650,1974$.

22. Bean, H. S. (ed.), "Fluid Meters - Their Theory and Application", 6 th Edition, ASME, New York, 1971.

23. Bajura, R. A., and Pellegrin, M. T., "Studies of Pulsating Incompressible Flow Through Orifice Meters", NBS SP 484, Oct. 1977.

24. Keyser, D. R., "Unsteady Orifice Flow Measurements, Its Theory and Observations", In: Flow - Its Measurement and Control in Science and Industry, Vol. 2, 1981, ASME, ISA, NBS Conference, St. Louis, MO, published by ISA, Raleigh, NC.

25. Mottram, R. C., "Measuring Pulsating Flow with a Differential Pressure Meter", In: Flow - Its Measurement and Control in Science and Industry, Vol. 2, 1981, ASME, ISA, NBS Conference, St. Louis, MO, published by ISA, Raleigh, NC.

26. Toyota, H., "Pressure Fluctuations and Pulsation Error of Differential Pressure Gas Flow Meters", IMEKO Tokyo Flow Symposium, Nov. 1979, published by SICE, Tokyo, Japan.

27. Caen, R. and Pignemal, J., "Errors in Differential Pressure Flowmeters Due to Pressure Fluctuations", FlOMEKO, Groningen, The Netherlands, Sept. 1978, published by North-Holland Publishing Co., Amsterdam. 
28. Rayle, R. E., "Influence of Orifice Geometry on Static Pressure Measurements", ASME Paper 59-A-234, 1959.

29. Benedict, R. P., "Fundamentals of Temperature, Pressure, and Flow Measurement", Wiley, New York, 1977.

30. Gorter, J., "Deformation of Orifice Plates; Theory and Practice", FLOMEKO, Groningen, The Netherlands, September 1978.

31. Report of the Joint AGA-ASME Orifice Coefficient Comittee, 1935. (This document has been reprinted by the Thermodynamics Research Center of Texas A\&M University, 1981.

32. American Gas Association, Orifice Metering of Natural Gas, Report No. 3, Chapter 14, Section 3, (also referred to as American Petroleum Institute Manual of Petroleum Measurement Standards, American National Standards Institute/American Petroleum Institute 2530), 1978.

33. Irving, S. J., "The Effects of Bends on the Discharge Coefficient of Orifice Plates", FlOMEKO, Groningen, The Netherlands, September 1978, published by North Holland Publishing Co., Amsterdam.

34. Startett, P. S., Nottage, H. B., and Halfpenny, P. F., "Survey of Information Concerning the Effects of Non-Standard Approach Conditions Upon Orifice and Venturi Meters", ISA Reprint of ASME Ppaer 65-WA/FM-5, 1966.

35. Martin, C.N.B., "Effects of Upstream Bends and Valves on Orifice Plate Pressure Distributions and Discharge Coefficients", International Journal of Heat and Fluid Flow, Vol. 3, No. 3, Sept. 1982.

36. Kinghorn, F. C., "Flow Measurement in Swirling or Asymetric Flow - A Review", Flow-con 77 Proceedings, Institute of Measurement and Control, Gatton and Kent, U.K., 1977.

3.7. Zanker, K. J., "The Development of a Flow Straightener for Use with Orifice Flow Meters in Disturbed Flow", Symposium on Flow Measurement in Closed Conduits, paper D-2, NEL, East Kilbride, Scotland, U.K., 1959.

38. Akashi, K., et al., "Development of a New Flow Rectifier for Shortening Upstream Straight Pipe Lengths in Front of Flow Meters", IMEKo-Tokyo Flow Symposium, November 1979, published by SICE, Tokyo, Japan.

39. Davis, R. W., Moore, E. F., and Mattingly, G. E., "Designing Tortuous Flow Conditioners Using Computer Modeling Techniques", (unpublished results) NBS, 1978.

40. Goldstein, R. J., "Fluid Mechanics Measurements", Hemisphere Publishing Corp., 1983.

41. Mattingly, G. E., "The Hydrogen Bubble Flow Visualization Technique", U.S. Navy DTMB Rept. 2146, 1964. 
42. Bates, C. J., "LDA Measurements of the Flow Through an Orifice Plate", In: Flow - Its Measurement and Control in Science and Industry, Vol. 2, St. Louis, MO, 1981, published by ISA, Raleigh, NC.

43. Mattingly, G. E. and Davis, R. W., "Numerical Solutions for Laminar Orifice Flow", ASME Paper 77-WA/FE-13, Dec. 1977.

44. Davis, R. W. and Mattingly, G. E., "Numerical Modeling of Turbulent Flow Through Thin Orifice Plates', NBS SP 484, Oct. 1977.

45. Ashmawey, M. F., "Investigation of Laminar Flow Through a Flow Meter", MSME Thesis, Univ. of Alexandria, Alexandria, Egypt, 1982.

46. Davis, R. W. and Moore, E. F., "A Numerical Study of Vortex Shedding from Rectangles", Journal of Fluid Mechanics, Vol. 116, pp. 475-502, 1982.

47. Davis, R. W., Moore, E. F., and Purtell, L. P., "A Numerical-Experimental Study of Confined Flow Around Rectangular Cylinders", Physics of Fluids, 27 (1), Jan. 1984.

48. Yeh, T. T., Robertson, B., and Mattar, W. M., "LDV Measurements Near a Vortex Shedding Strut Mounted in a Pipe", Journal of Fluids Engineering, ASME, Vol. 105, Pp. 185-196, June 1983. 


$$
\text { LIST OF TABLES }
$$

Table

1

2

3

4
Title

Fluid Metering Research

Flow Measurement Devices

Causes for Deviations from Ideal Orifice Performance

Experimental Techniques for Orifice Flow 


\section{LIST OF FIGURES}

Table

1

$2(a)$

2(b)

3

4(a)

4(b)

5

6

7

8

9

10

11

12

13
Title

Orifice Flow-The Axisymmetric Ideal

Plate Bending Effects

Plate Beveling Effects

Inlet Flow - Linear Velocity

Inlet Flow - Swirl Velocity - The Effects of an Elbow

Inlet Flow - Swirl Velocity - The Effects of Two Elbows

Pi tot Tubes

Anemome try

Visualization - Smoke Wire

Smoke Wire Results

Visualization - Dye Injection

Visualization - Electrolysis - Hydrogen Bubble

Laser Doppler Velocimetry (LDV)

LDV Orifice Profiles

Optical Techniques - Interferometry 


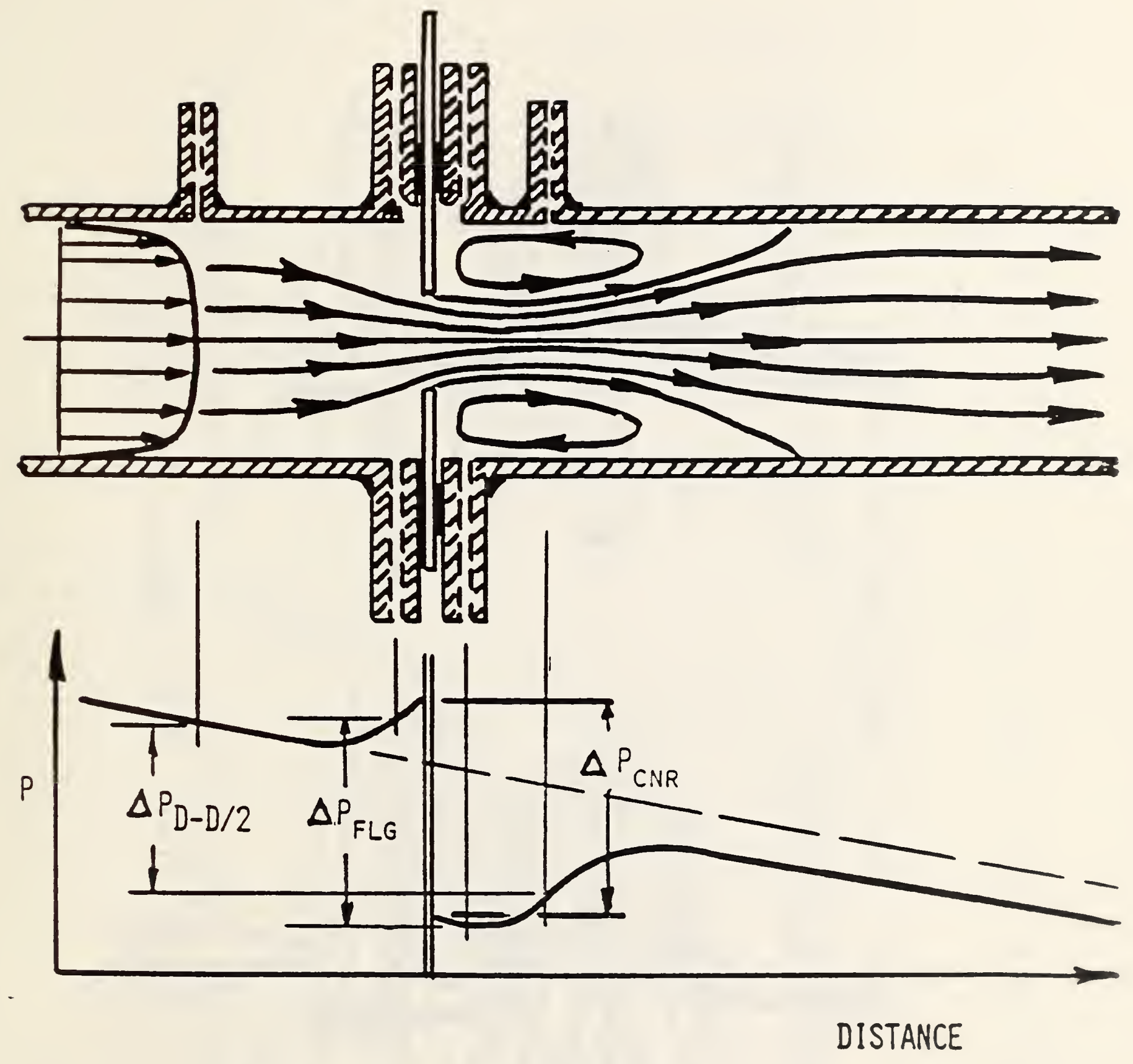

Fig. 1. Orifice Flow-The axisymmetric Ideal 


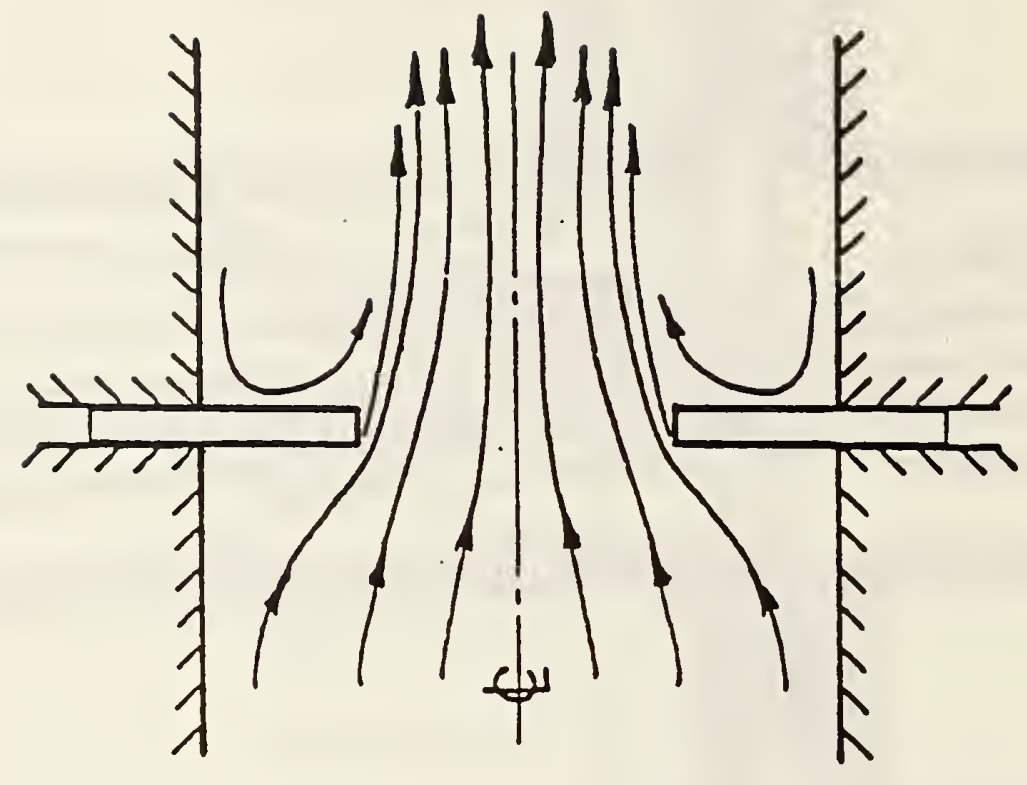

$\omega$
$u$
$u$
$u$
$u$
$u$
0
$z$
0
$z$
$u$
2
$w$
5
$\square$
0

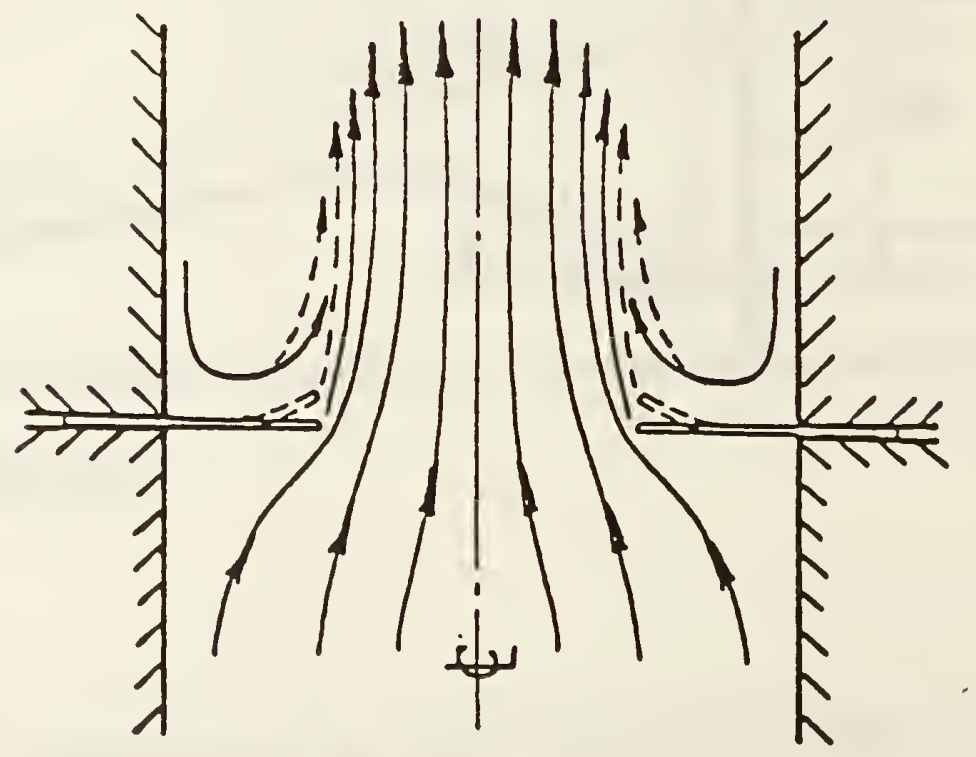

$\stackrel{\dot{s}}{\stackrel{\dot{s}}{\circ}}$ 


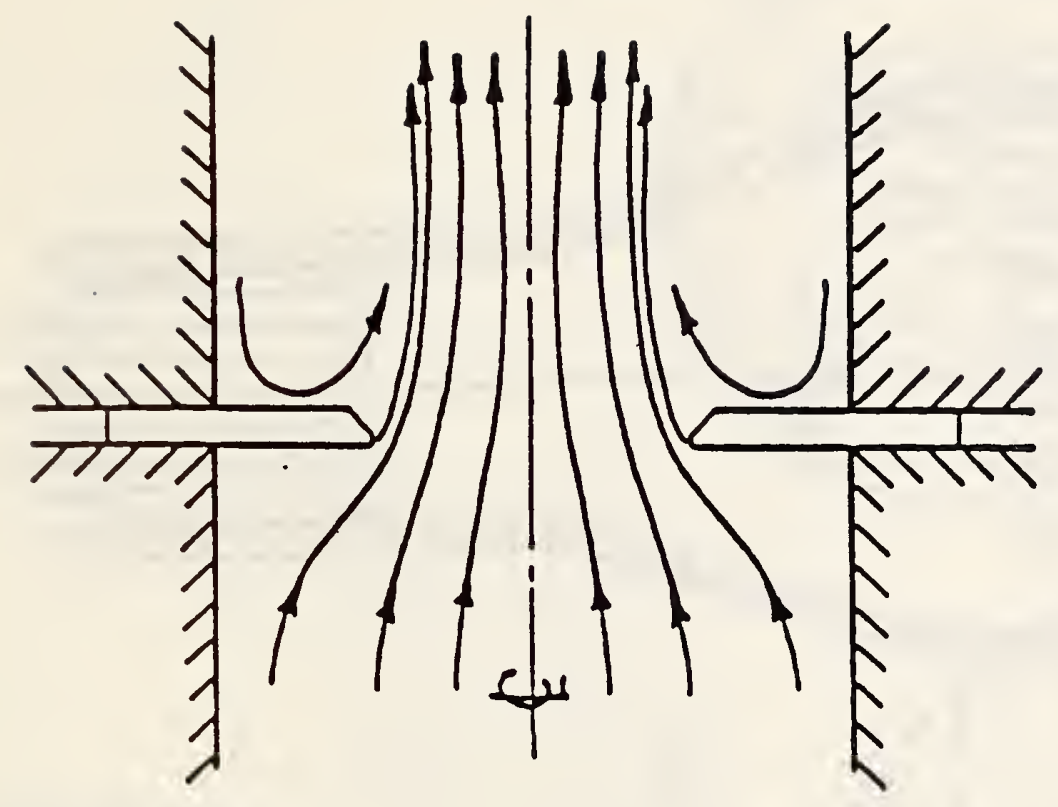

$w$
$u$
$u$
$u$
$u$
0
$z$
$\frac{1}{w}$
$\frac{\omega}{w}$

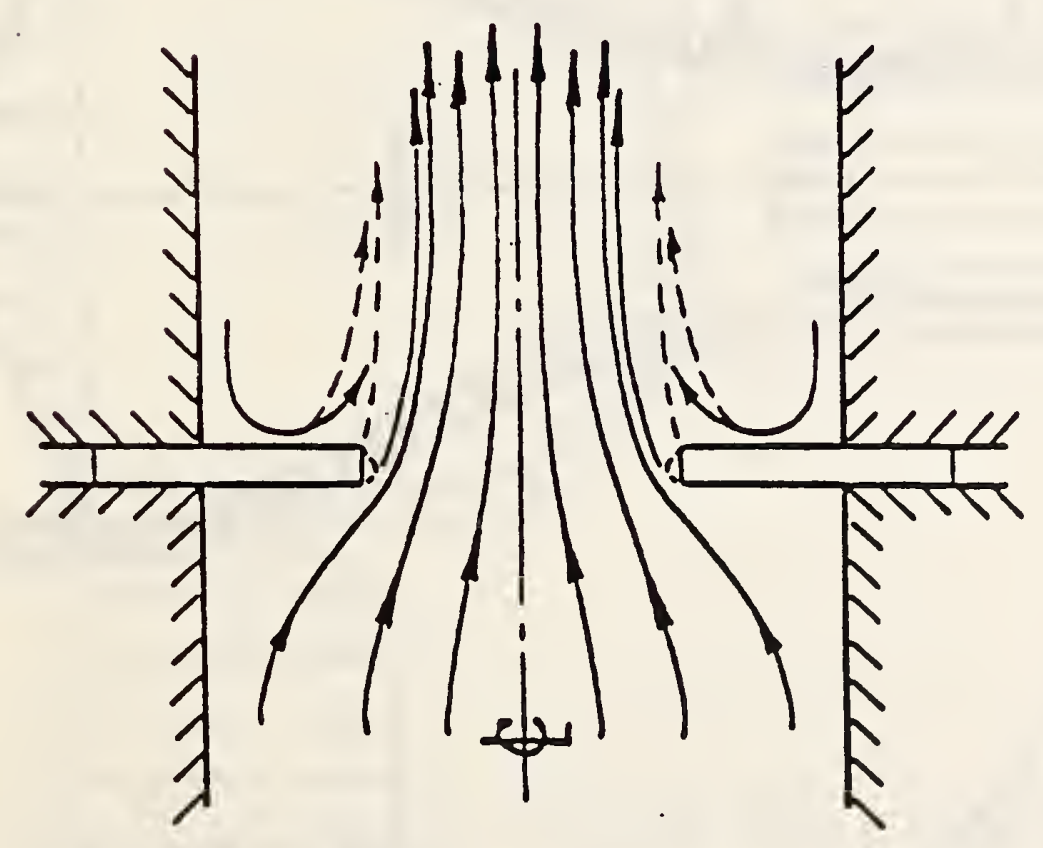

占

$\frac{\dot{\infty}}{\sim}$

$\frac{\dot{0}}{4}$ 
Effiects of Pipe Transitions
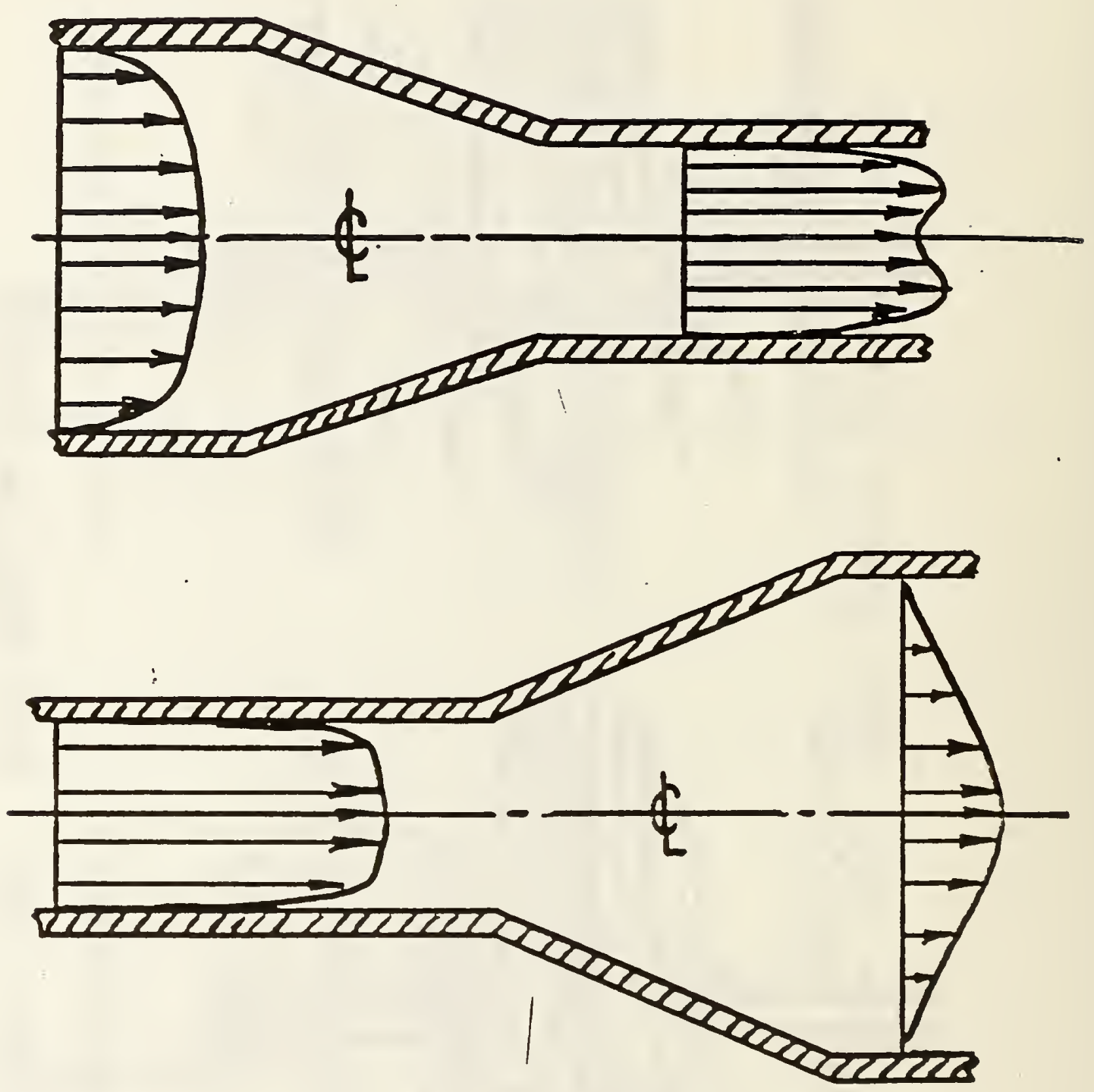

fig. 3. Inlet flow - linear velocity 


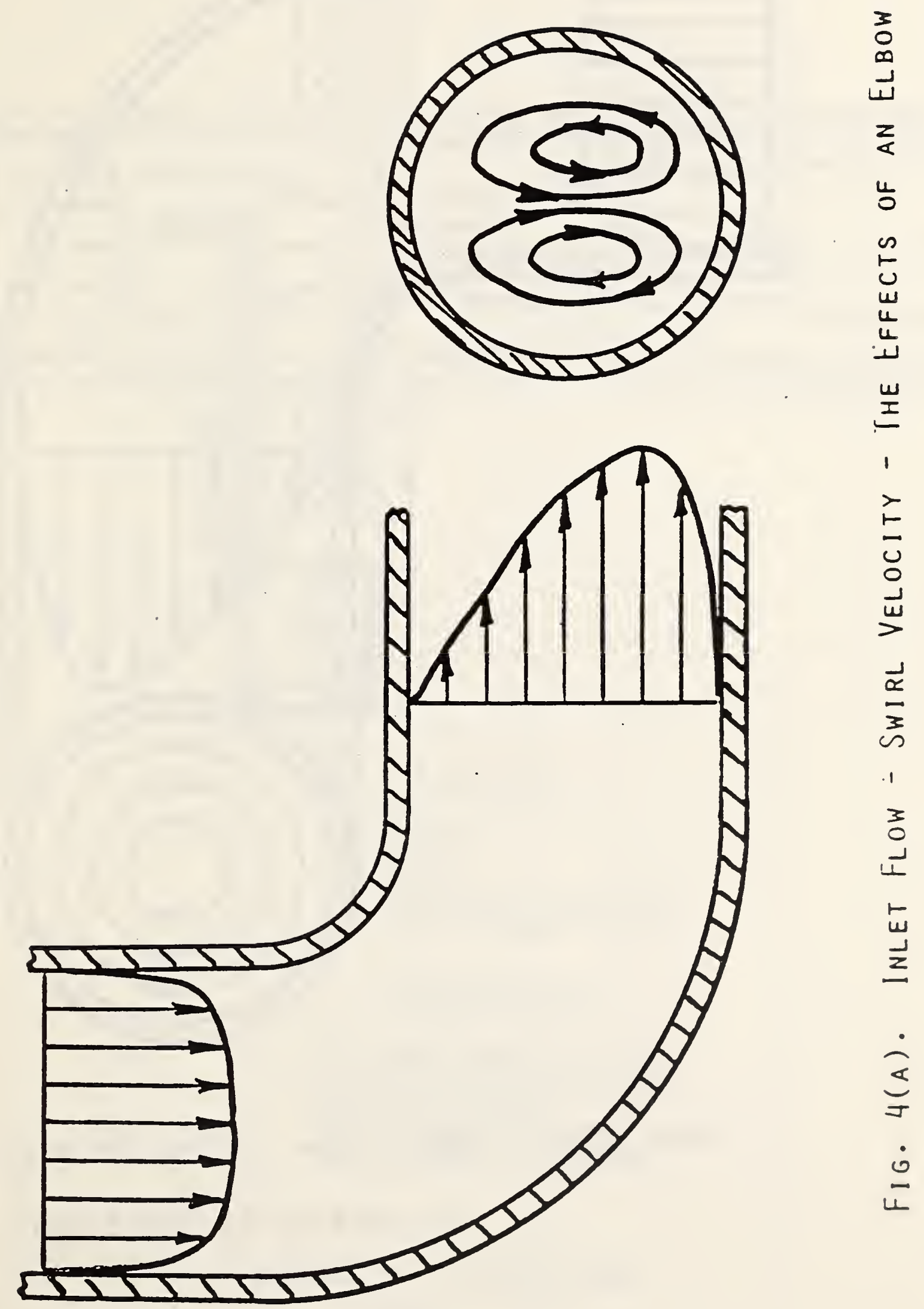

A4. 21 


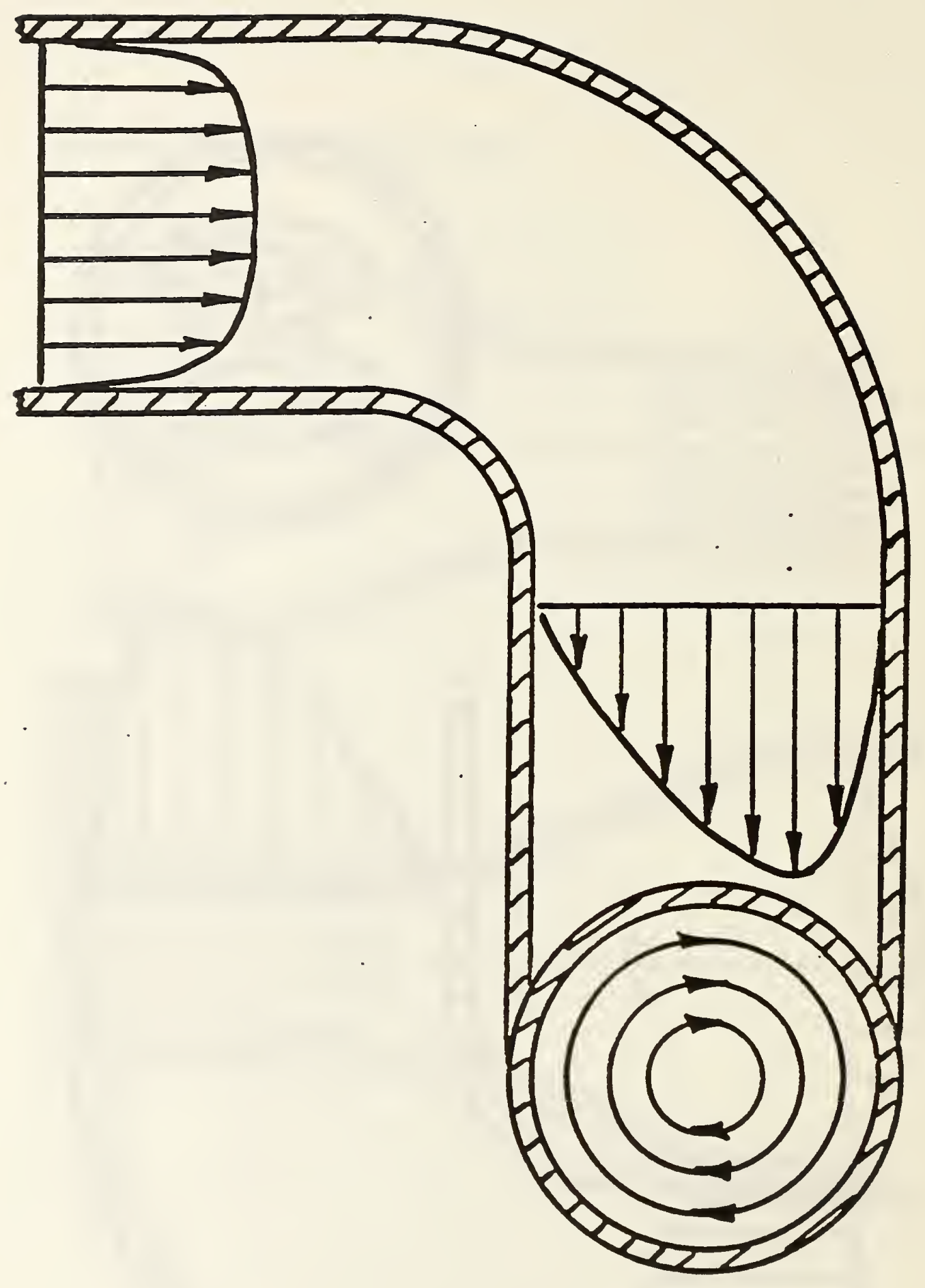

FIg. 4(B). InLET Flow - SWIRL Velocity The Effects of Two Elbows 


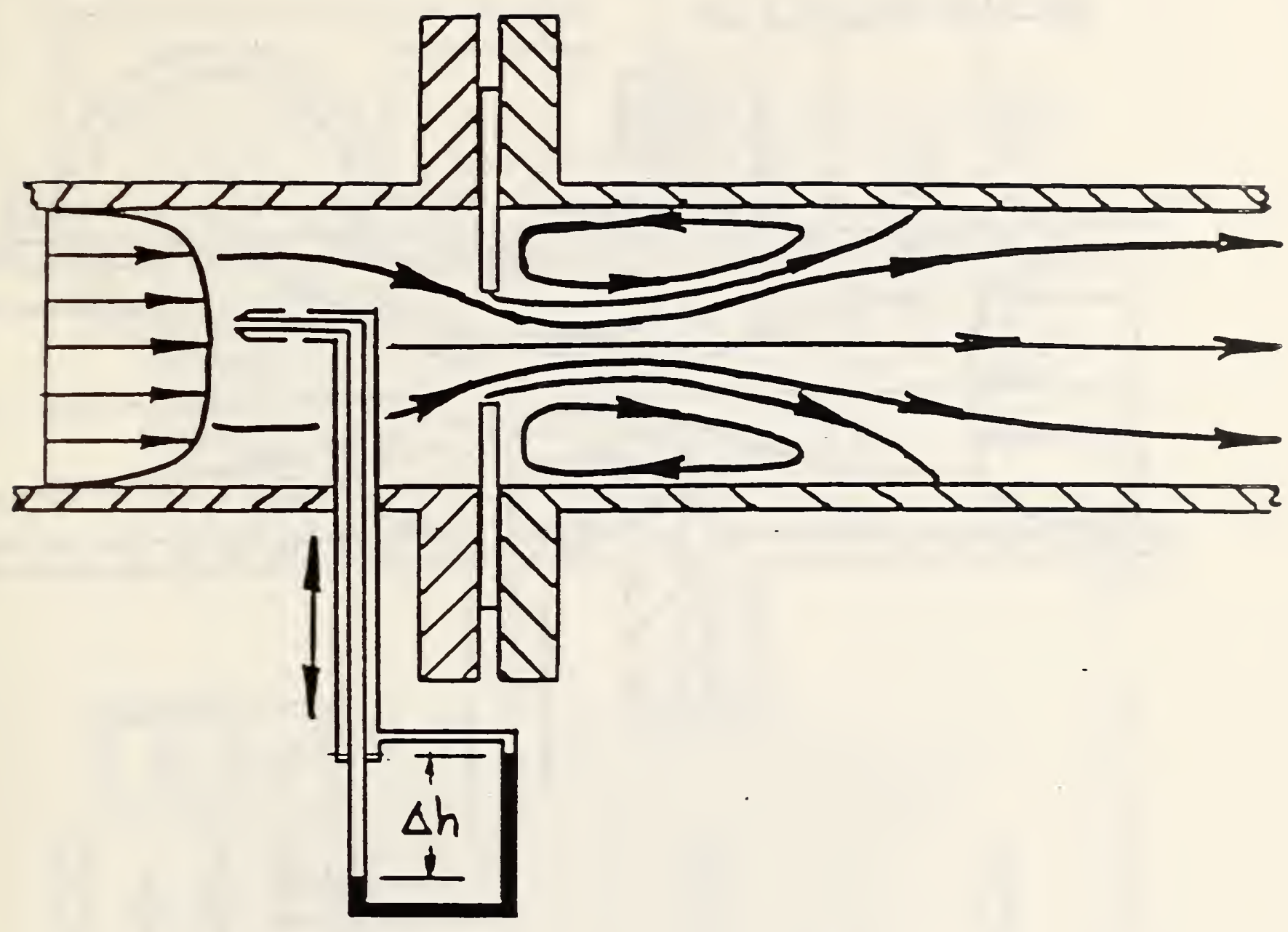

ADVANTAGES

1) SiMPLE

2) CHEAP

3) RUGGED

4) Multiholed versions

FOR SECONDARY FLOW

\section{DISADVANTAGES}

1) LARGE SENSING VOLUME

2) NON LINEAR PRINCIPLE

3) SLOW RESPONSE

4) LOW VELOCITY LIMIT

5) CALIBRATION NEEDED

Fig. 5. Pitot tube 


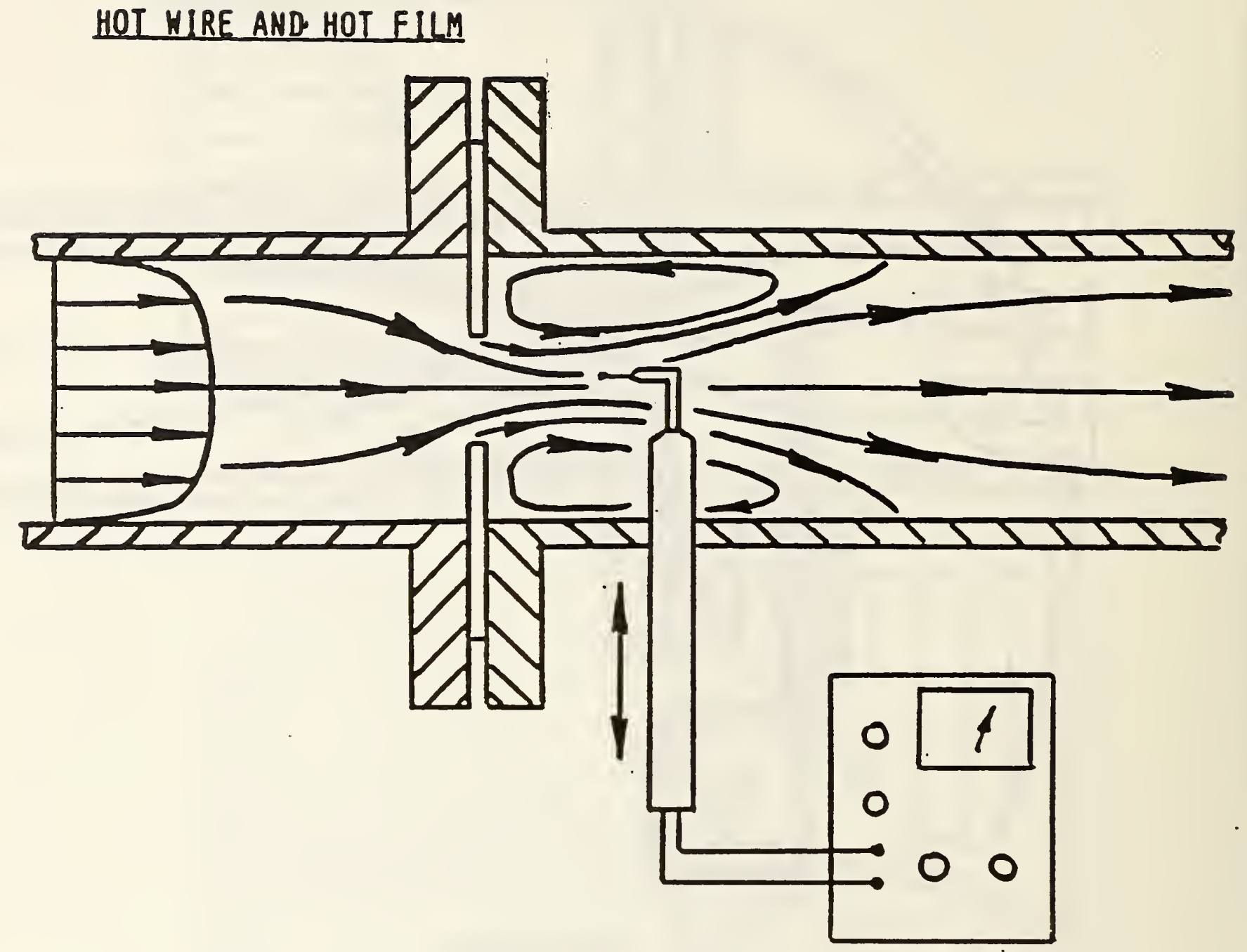

\section{ADVANTAGES}

1) SMALL SENSING VOLUME

2) FREQUENCY RESPONSE - VERY GOOD

3) MULTISENSOR PROBES

\section{DISADVANTAGES}

1) NON LINEAR PRINCIPLE

2) SENSORS ARE DELICATE

3) LOW VELOCITY LIMIT

4) CALIBRATION NEEDED

Fig. 6. Anemometry 

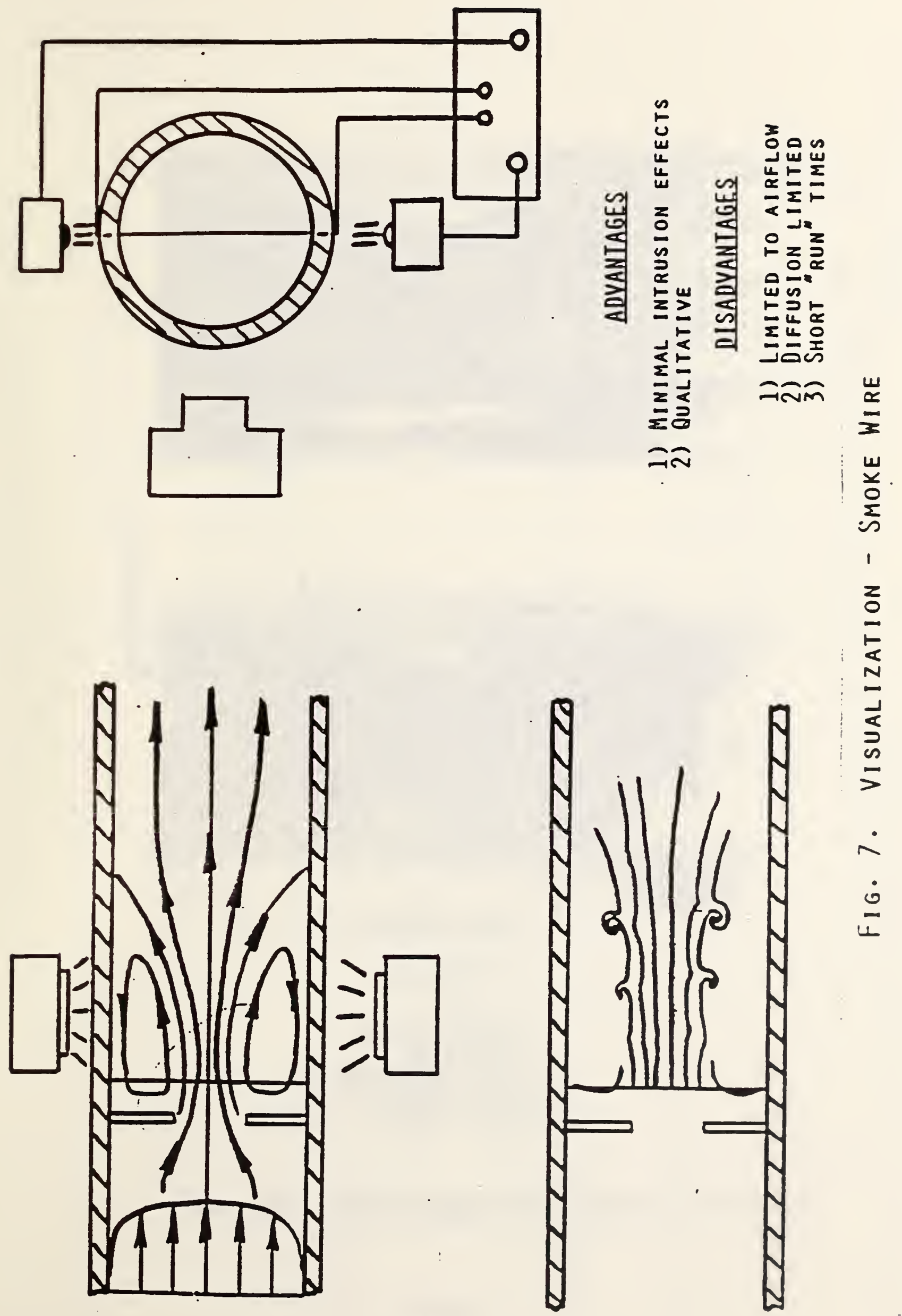

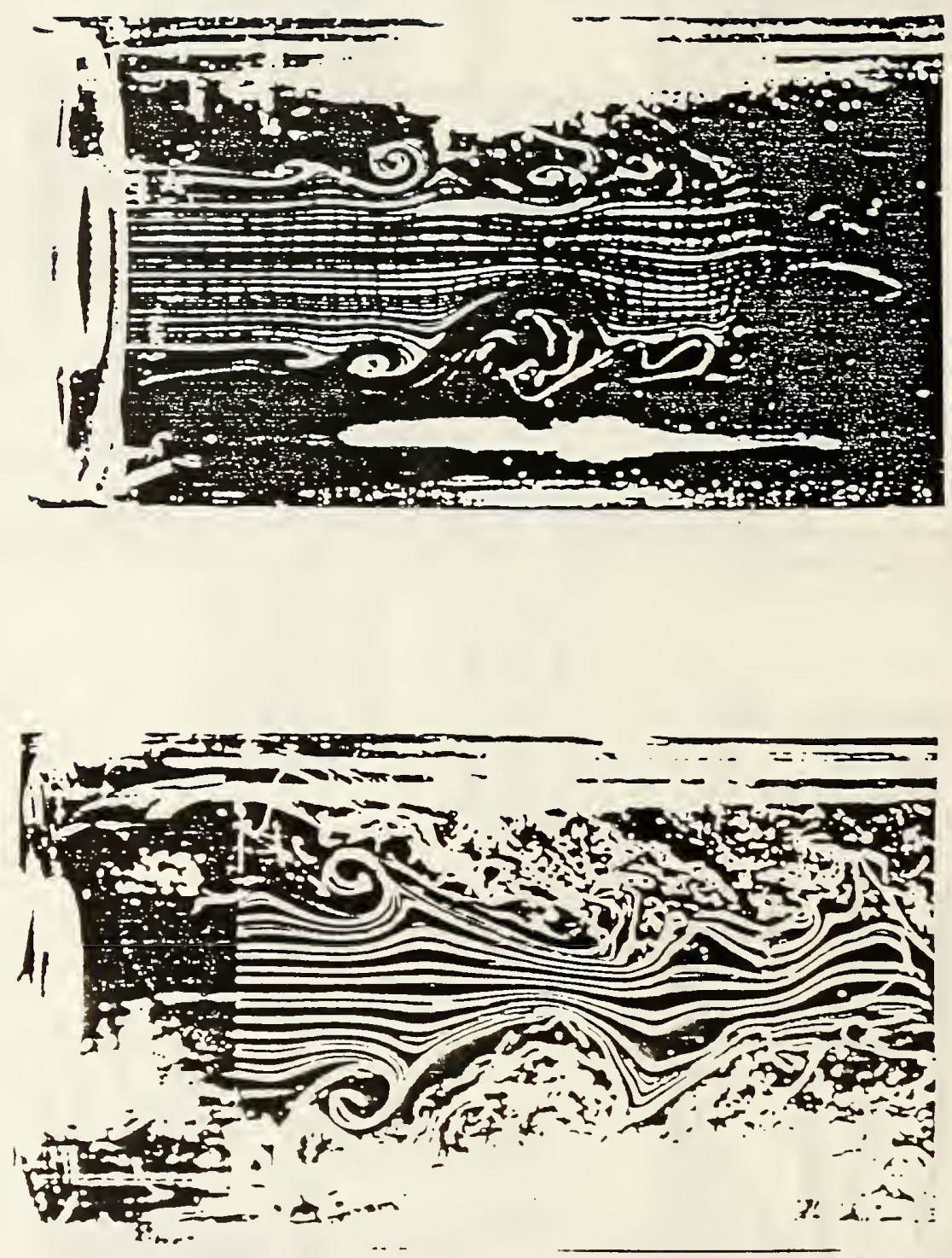

Fig. 8. SMOKE WIRE RESULtS 

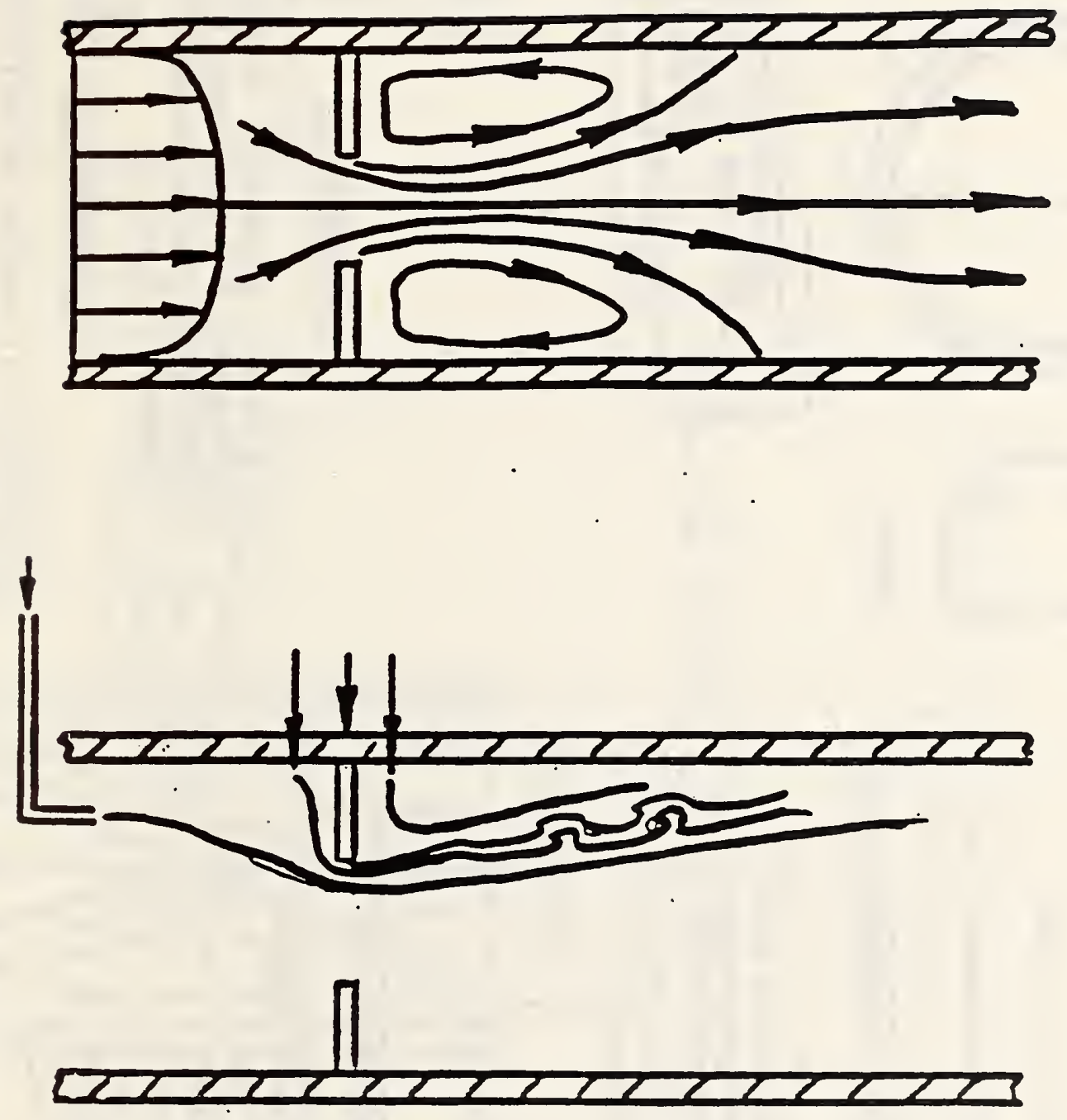

ADVANTAGES

1) Simple

DISADVANTAGES

1) DIFFUSiON LIMITED

2) Contaminates Fluid

Fig. 9. Visualization - Dye Injection 

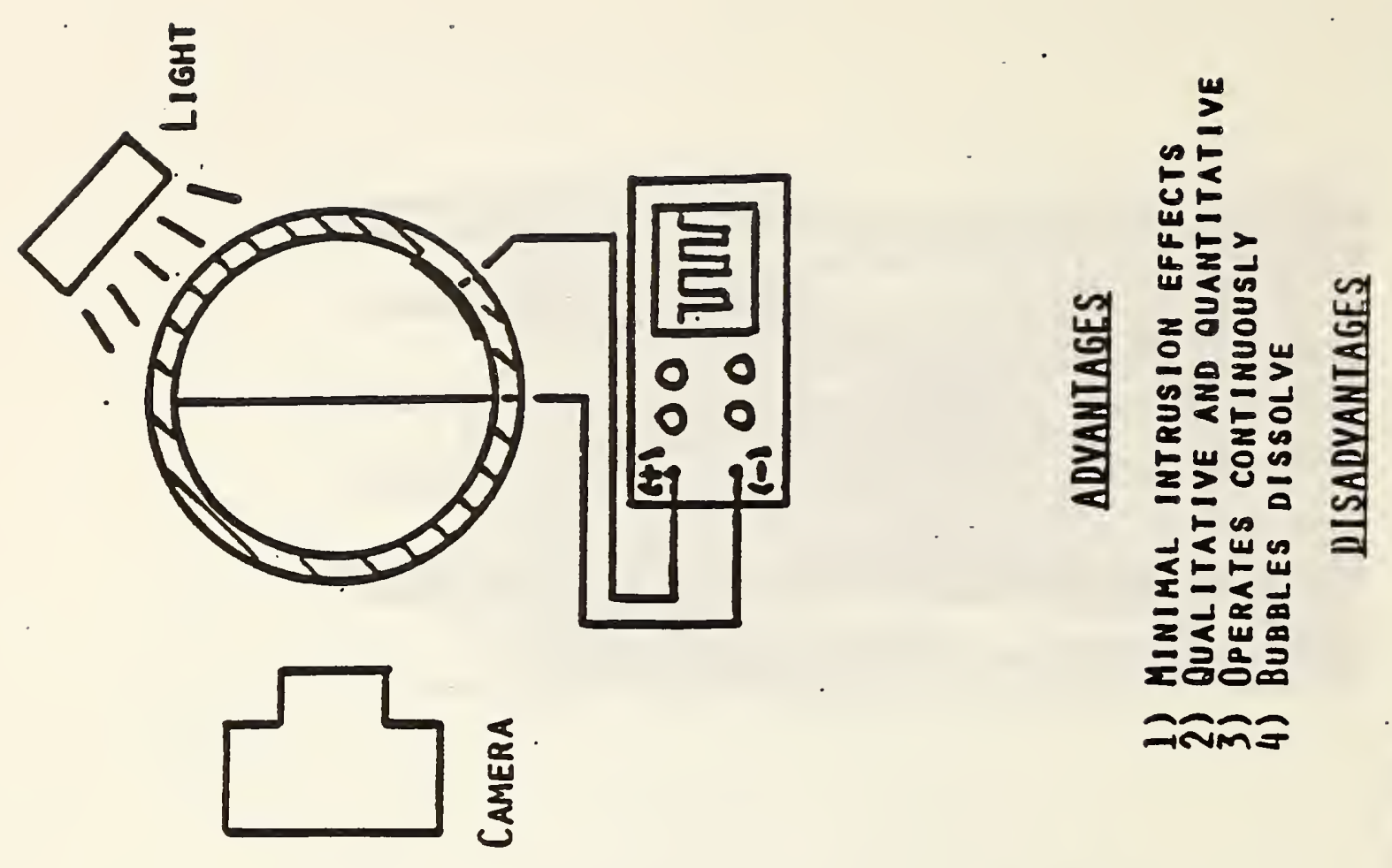

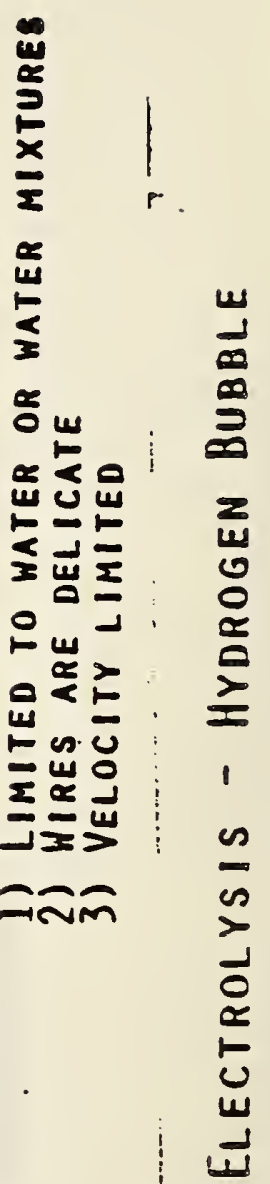
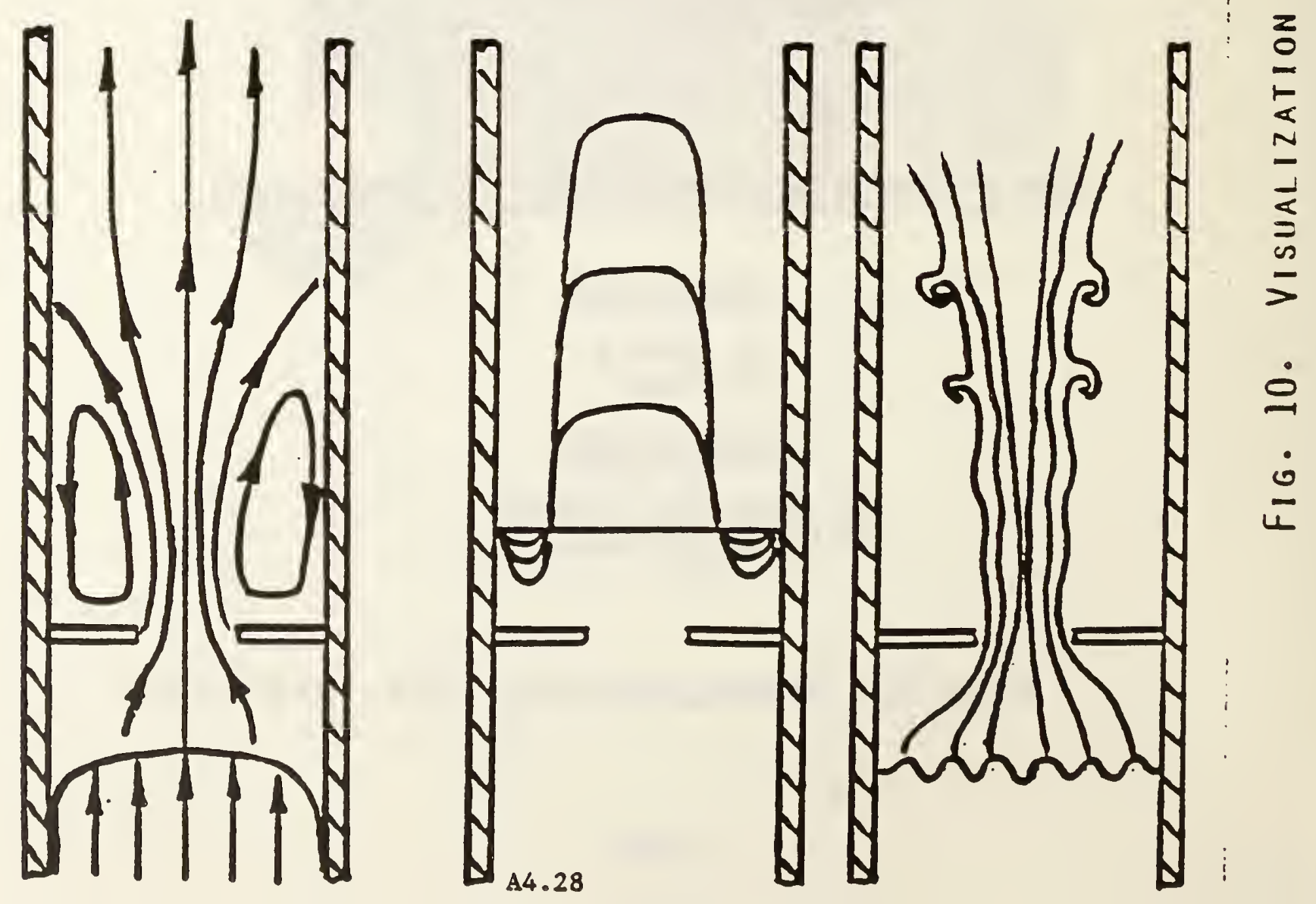


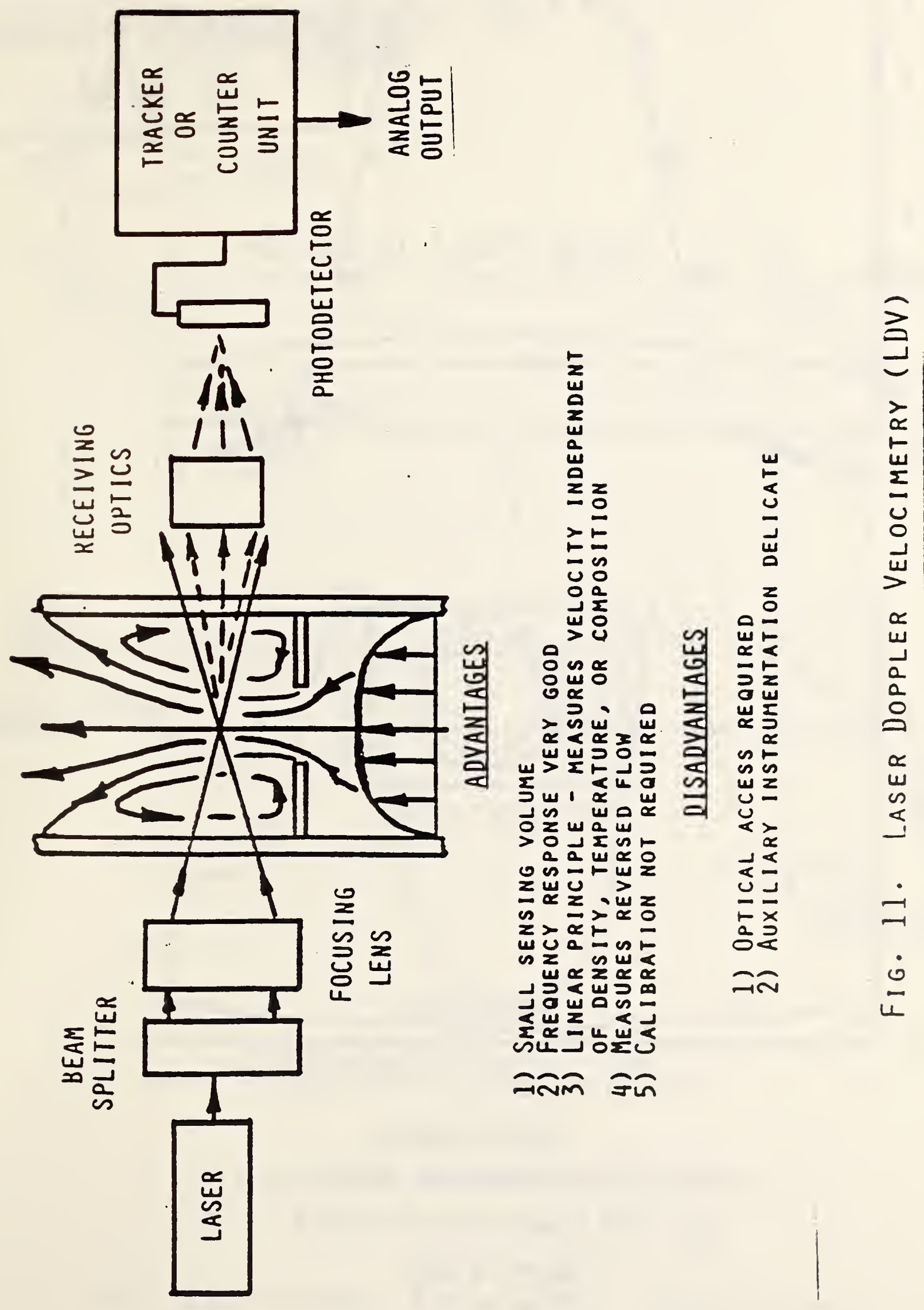



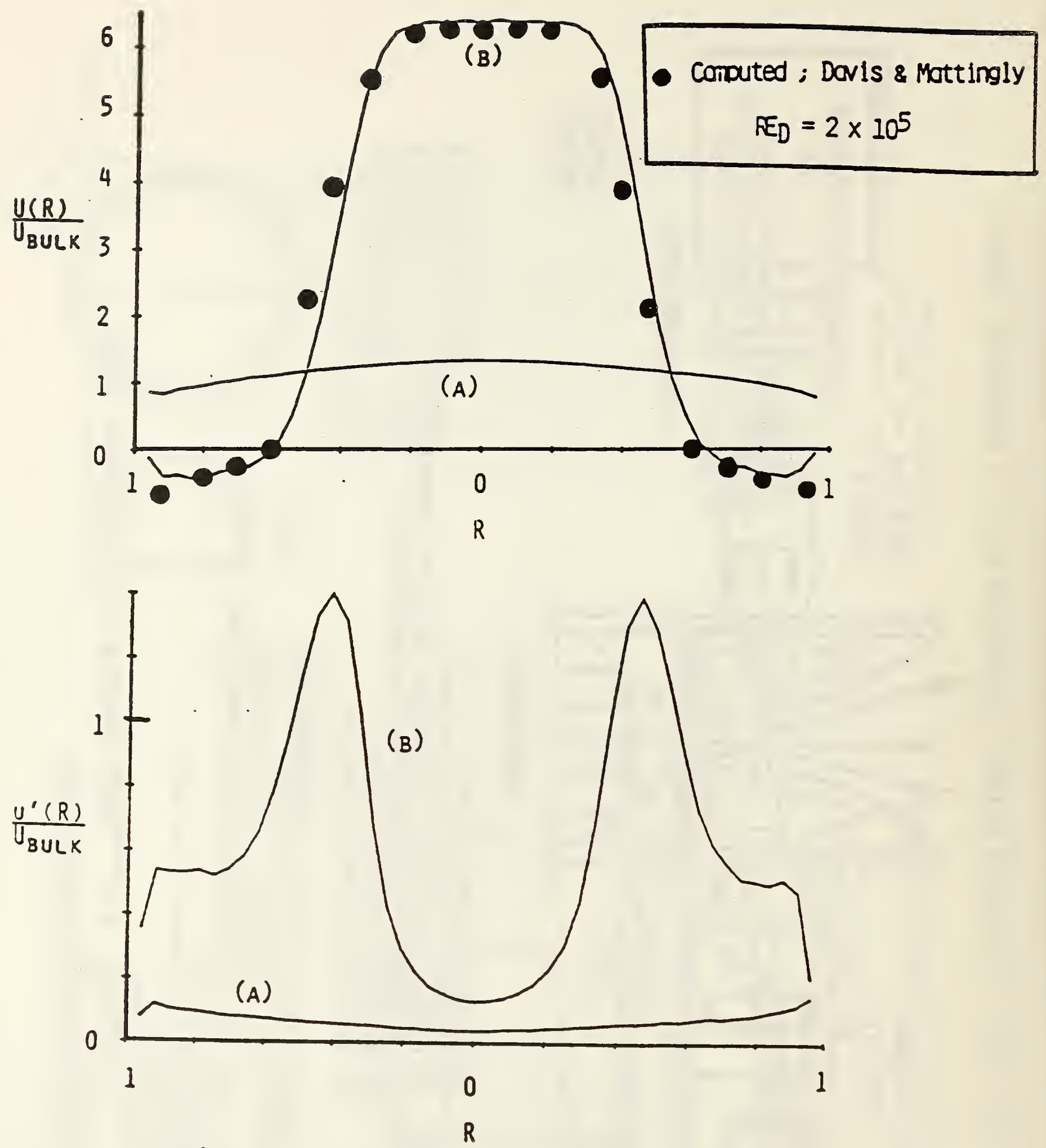

(A) D/2 UPSTREAM OF PLATE

(B) D/2 DOINSTREAM OF PLATE $P E_{D}=5 \times 10^{4}$

FIg. 12. LDV ORIfice Profiles A4. 30 


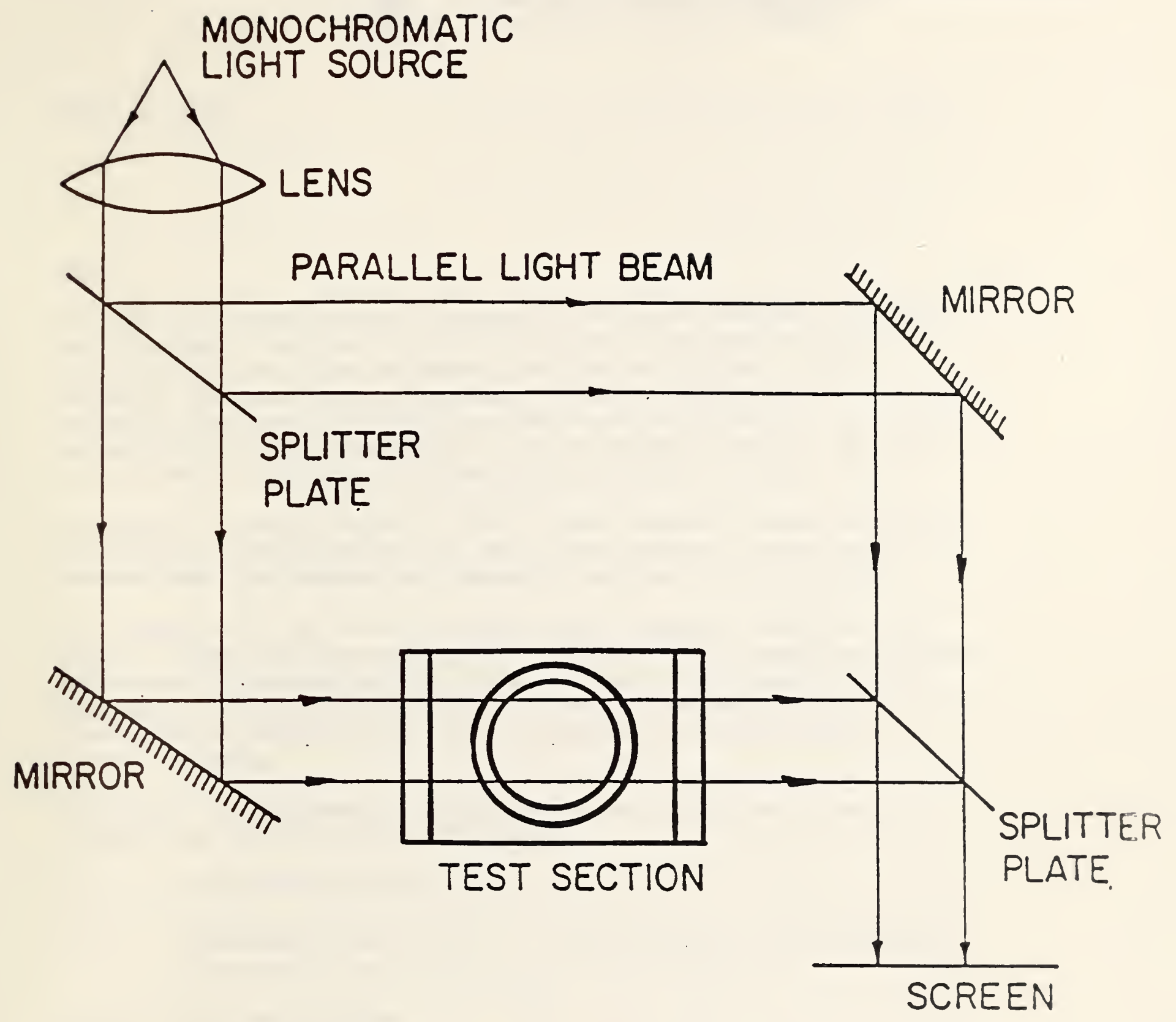

\author{
ADVANTAGES \\ 1) Frequency response - goOd \\ 2) QUALITATIVE and QUANTITATIVE \\ DISADVANTAGES \\ 1) Results are averaged along light path
}

Fig. 13. Optical techniques - Interferometry 


\section{Dear:}

You, or your representative, are invited to participate in a workshop being planned to address industrial concerns in thermal metering i.e., the flow of steam and water (both hot and chilled). The workshop, sponsored by the Department of Energy (DOE) and the National Bureau of Standards (NBS) with the assistance of industry representatives (IDHA and $\mathrm{NADHCI}$ ), will be convened for two days, May 21-22, 1984 at the Sheraton Potomac Inn, Rockville, MD near NBS.

Attendance is being planned so that a broad range of interests will be represented. Specifically, U.S. meter manufacturers, meter users, academicians, and appropriate standards personnel will be present.

The workshop will not involve product advertisements, exhibits, or hardware items from any manufacturer. Consequently, manufacturers are encouraged to choose a representative from their technical staff (as opposed to their sales staff) who will be able to contribute to discussions of issues and potential solutions required to improve thermal metering.

Currently, it is planned for attendees to form into task groups to address five topical areas as follows:

Topic 1 - Installation Effects

Topic 2 - Measurement Techniques for Thermal/BTU Flow and Performance Characteristics

Topic 3 - New Technologies

Topic 4 - Traceability of and Standards for Measurements for Thermal/BTU Flow

Topic 5 - Control Systems Management 
Within each of these topical areas, such aspects as costs, benefits, effects on accuracy, technology, etc. will be discussed.

The two day format is sketched as follows:

Day 1 - May 21

Opening - Welcome

Statement of Workshop Purpose

Identification and

Discussion of Issues

Lunch

Attendees formed into

Task Groups

Task Group Sessions

Ad journ
Day 2 - May 22

Task Group Chaimen present results to all at tendees

Discussion by all attendees of results ("cross-fertilization")

Lunch

Task Groups reconvene

Final Session - Summaries and

Balloting to Prioritize Issues

Ad journ

A wine and cheese get-together is scheduled for Sunday evening, May 19, at 7:00 PM at the Sheraton Potomac Inn.

On Wednesday morning, May 23, a brief tour of the NBS Fluid Mechanics and other laboratories is offered for those interested.

We will appreciate it if you would return the enclosed form so that we can finalize plans. It is essential that we receive your response by April 20, 1984.

There will be a $\$ 35.00$ registration fee to cover reception, coffee, two lunches (May 21 and 22) and a dinner on May 21. Each participant will have to pay for lodging, other meals, etc. Please make reservations by May I by calling 800-638-8559 making sure to mention that your room is in the block of rooms reserved for the "NBS-DOE Conference to obtain the discount room rate.

Should you have questions, please feel free to contact me.

Dr. George E. Mauhngly

Senior Scientist for Fluid Measurements

Chemical Process Metrology Division

Center for Chemical Engineering

Enclosure 
Thermal Metering Workshop

1. I suggest that the following items be added to the topical areas given above:

2. I believe that the key issues (i.e., cost, accuracy, etc.) in thermal metering are:

1.

2.

3.

3. In my view the things that are needed to resolve the above issues (i.e., research, meter performance standards, etc.) are:

1.

2.

3.

4. / Yes, I am interested in attending this two-day (May 21-22, 1984) workshop.

5. My prioritized preferences for my task group participation are:

1. Installation Effects

2. Measurement Techniques

3. New Technologies

4. Traceability and Standards

5. Control Systems

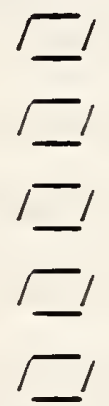

6. I No, I will not be able to attend.

7. Ies, I would like to receive the report resulting from this workshop.

Name:

Addres 8:

Phone:

A5. 3 



\section{Appendix 6}

\section{DOE-NBS THERMAL METERING WORKSHOP}

The following are responses received from the letter inviting you to this workshop.

1. Compended "Suggestions": (Question 1)

- Identify flow measurement accuracy required for various user areas.

- International standards vs. U. S. Standards.

- Telemetering/computer interfaces.

- Develop standards and guidelines for thermal meters.

- Small, comercial (multi-family) master metering.

- Establishing standards for BTU meters.

- Minimum cost instrumentation.

- Maintenance requirements.

- Maintenance and calibration-setting up a two-meter shop.

2. Compended "Key Issues": (Question 2)

- Research on valid operating principals

- Field testing of meter accuracy

- Feedback from users - building owners, tenants, utilities

- Installation practice $1 *$

- Pressure and temperature compensation

- Accuracy 1411

- Rangeability 11

- Costs 1111

- Traceability

- Standardization
- Set accuracy 8 tandards for different meter usages

- Selection of meters and sizing

- Handling of meters

- Predictability

- Variability of performance due to installation and operational factors.

- ROI

- Processes

- Precision 1

- Recording medium

- Reliability 1

*Marks denote repeats 
- Economics 1

- St andardization

- Accuracy as related to cost

- In place calibration
- Minimum cost flow meters

- Ease of installation and interfacing to controls 1

- Frequency of repair

3. Compended "Needs": (Question 3)

- System performance standards (not BTU meter standards).

- Standardized identification of performance capabilities of various metering systems.

- Recommended proper installation for each metering system.

- Fluid condition effects (steam, etc.)

- Commitment to research

- Standards and standardization

- Performance standards 11 *

- Performance recomendations

- R\&D to develop a reliable cost, efficient meter.

- Research 111

- Utilization of Field Experience

- Performance testing

- $R \& D$

- Testing of all BTU meters with established testing methods.

- Standards

- Sharing of information among users

- System optimization

*Marks denote repeats 
Appendix 7

\section{DOE-NBS Thermal Metering Workshop \\ Sherat on-Potomac Inn \\ Gaithersburg, MD}

\section{MONDAY, MAY 21}

\section{$8: 30$ BALLROOM A - Coffee}

\section{9:00 BALLROOM A}

NBS Opening (G. E. Mattingly) Chief, Chemical Process Metrology Division)

DOE Welcome and Introduction

( $J$. Kaminsky, Office of Conservation)

\section{Issues:}

Overview - J. Kaminsky

Metering Issues in District Heating and Cooling:

N. R. Taylor, Int'I. Dist. Heat. Assoc. (IDHA), P. L. Turchi, Chrmn. IDHA Comm. on Fluid Metering and ADCONS, Inc.,

C. W. Phillips, NADHCI.

Fluid Metering Research: New Tools and New npportunities: G. E. Mattingly

Coffee Break

Responses to Invitation

Discussions

12:00 LUNCH - ATRIUM

1:00 BALLROOM A - Task Group Formation

1:30 BREAKOUT ROOMS - Task Group Sessions

3:00 Coffee - BALLROOOM A

5:00 Adjourn

7:00 DINNER - ATRIUM

\section{AGENDA}

TUESDAY, MAY 22

8:30 BALLROOM A - Coffee

9:00 BALLROOM A - Task Group Presentations of Results "Cross-Fertilization" and Discussions

Coffee Break (midway)

2:00 LUNCH - ATRIUM

1:00 BREAKOUT ROOMS - Implement at ion of "Cross-Fertilization" and Production of Major Issues and Associated Research Projects

3:00 Coffee - BALLROOM A

3:20 BALLROOM A - Final Session Grand Ballot

4:30 Ad journ 


\section{Task Group Facilitators}

Task Group 1 - Installation Effects

Professor William Durgin

Department of Mechanical Engineering

Worcester Polytechnic Institute

Worcester, MA

Task Group 2 - Measurement Techniques

Professor James Murdock

Department of Mechanical Engineering

Drexe 1 University

Philadelphia, PA

Task Group 3 - New Technologies

Professor Dirse Sallet

Departments of Mechanical Engineering and

Chemical and Nuclear Engineering

University of Maryland

College Park, MD

Task Group 4 - Traceability and Standards

Professor Thomas Arnberg

Departrent of Mechanical Engineering

University of Colorado - Denver

and

Colorado Engineering Experiment Station, InC. (CEESI)

Nunn, CO

Task Group 5 - Control Systems

Dr. James Hill

Chief, Building Equipment Division

Center for Building Technology

National Bureau of Standards

Gaithersburg, $M$

and

Mr. Narender Reddy

Energy \& Environmental Systems

Argonne National Laboratory

Argonne, IL 
List of Attendees

THERMAL METERING WORKSHOP

May 21-22, 1984

Wallace Alspach

EMCO

Longmont, CO

Norman Alston

Dieterich Standard Corp.

Boulder, CO

Bernhard Ams tutz

ISTA Energy Systems

Roselle, NJ

Jim Anderson

EGSG Idaho

Idaho Falls, ID

Professor T. Arnberg

University of Colorado-Denver

and CEESI

Nunn, CO

Bernard H. Barnett

Sonseboz Corp.

Plainview, NY

Ken Benson

NBS

Dr. Martin Bernard

Argonne National Lab

Argonne, II

John Brennan

Spence Engineering Co.

Walden, NY

Professor E. F. Brown

VPI \& SU

Blacksburg, VA

Thomas H. Burgess

Fischer \& Porter Co.

Warminster, PA

Alfredo Cacaindin

Arling ton, VA
Professor R. V. Calabrese

Dept. Chem. \& Nuc. Engineering

University of Maryland

Harry C. Cartledge

Schuylkill General Station

Philadelphia, PA

Michael Celinski

Brooklyn Union Gas

Brooklyn, NY

Richard Chea tham

EFF Co.

Dallas, TX

Frank Childs

EG\&G Idaho

Idaho Falls, ID

Gary Corpron

Rosemount

Eden Prairie, MN

Nicholas R. Destefano

BIF

West Warwick, RI

Professor William Durgin

Worcester Polytechnic Inst.

Worcester, MA

E. V. Erjavaec

Meriam

Cleveland, $\mathrm{OH}$

Albert G. Ferron

Alden Research Lab

Holden, MA

Robert T. Fretz

Arling ton, VA

Charles Fuller

Wilgood Corp.

Chesapeake, VA 
Dr. Adolfas Gaigalas

NBS

Dr. Gerald Guinn

Alabama Solar Center

Huntsville, AL

Terri Hahn

Arling ton, VA

Peter Herzl

Fischer \& Porter Co.

Warminster, PA

James Hill

NBS

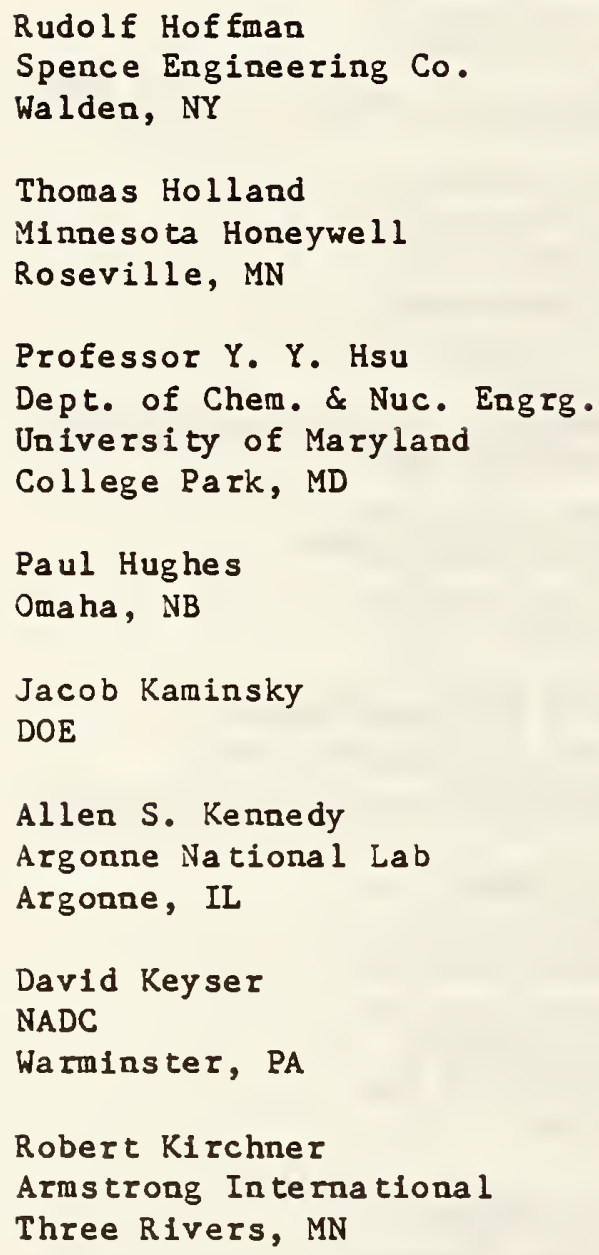

Rudolf Hof fman

Spence Engineering Co.

Walden, NY

Thomas Holland

Minnesota Honeywell

Roseville, MN

Professor Y. Y. Hsu

Dept. of Chem. \& Nuc. Engrg.

University of Maryland

College Park, MD

Paul Hughes

Omaha, NB

Jacob Kaminsky

DOE

Allen S. Kennedy

Argonne National Lab

Argonne, IL

David Keyser

NADC

Warminster, PA

Robert Kirchner

Armstrong International

Three Rivers, MN

Ronald N. Koch

North American Rockwell

Pittsburgh, PA

Tom Larsen

EG\&G Idaho

Idaho Falls, ID

Dr. Gerald Lewis

Argonne National Lab

Argonne, IL

Danny Lim

DOE

D. R. Mackay

NBS

George E. Mattingly

NBS

Richard K. Messock

NAVENENSVA

Port Hueneme, $\mathrm{CA}$

Alan Mitchell

Philadelphia Electric Co. Schuylkill General Station

Philadelphia, PA

Professor J. Murdock

Dept. of Mechanical Engineering Drexel University

Philadelphia, PA

Hans 0 . Nyman

District Heating Development

St. Paul, MN

John Petze

Andover Controls

Andover, MA

Charles Tilford

NBS

Clinton Phillips

NADHCI 


\section{Narender Reddy}

Argonne National Lab

Argonne, IL

Dr. B. Robertson

NBS

Professor Dirse W. Sallet

Dept. of Mechanical Engineering

University of Maryland

College Park, MD

Toshio Satori

Yokogawa Corp. of U.S.

Shenandoah, GA

Kirk Smith

EMCO

Longmon $t$, $c 0$

Robert Soulen

NBS

Clifford Spiegelman

NBS

David Spitzer

Nepara Chemical Co.

Harriman, NY

Edward P. Stephenson

Kent Meter

Ocala, FL

Norman R. Taylor

IDHA

Wa shing ton, DDCC

Stuart $W$. Temple

Hartford Steam Service

Hartford, CT

Peter L. Turchi

EMCO

ADCONS

Bal timore, MD
Dr. J. J. Ulbrecht

NBS

Willard Veeder

University of Rochester

Central Utilities

Rochester, NY

Chris Watson

ITT-Barton

City of Industry, $C A$

Larry M. Windingland

USA-CERL-ES

Champaign, IL

Ted Winick

Controlotron

Ha uppa uge, NY

Kan N. Yam

Con. Ed.

New York, NY 
NBS-IIAA (REV. 2-80)

U.S. DEPT. OF COMM.

BIBLIOGRAPHIC DATA

SHEET (See instructions)

1. PUBLICATION OR

REPORT NO.

NBSIR 85-3242

2. Performing Organ. Report Noy 3. Publication Date

DECEMBER 1985

4. TITLE AND SUBTITLE

A Report on the NBS-DOE May 1984 Workshop on Thermal Metering

5. AUTHOR(S)

G. E. Mattingly

6. PERFORMING ORGANIZATION (If joint or other than N8S, see in structions)

7. Conerace/Grane No.

MATIONAL BUREAU OF STAMDARDS

DEPARTMENT OF COMMERCE

WASHINGTON, D.C. 20234

8. Type of Report \& Period Covered Final

9. SPONSORING ORGANIZATION NAME AND COMPLETE ADDRESS (Street, City, Stote, ZIP)

U.S. Department of Energy

Office of Conservation

Washington, DC 20585

10. SUPPLEMENTARY NOTES

Document describes a computer program: SF-185. FIPS Software Summary, is attached.

11. ABSTRACT (A 200-word or less factual summory of most significont information. If document includes a significant bibliogrophy or literoture survey. mention it here)

A workshop on thermal metering (i.e., the flow of steam or of hot or chilled water) was convened in Gaithersburg, MD, May 21-22, 1984 to discuss and prioritize flowrate measurement problems and research programs which could lead to improved energy conservation through the development, acceptance, and use of district heating and cooling systems. The workshop brought together 60 attendees whose expertise spanned a broad range of interests. Included were flowmeter manufacturers, meter users, standards personnei, academicians, and consultants. Attendees listed current probiem areas and measurement needs in thermal metering, discussed appropriate responses to these needs, and prioritized these according to their perceived potential for impacting thermal metering practice. Leading this list are:

- "paper" standards witi special emphasis on "meter instailation requirements", - research on two-phase Elow and its measurement,

- two-phase flow tecinology transfer and information dissemination.

12. KEY WOROS (Six to twelve entries; alphabetical order; capitalize only proper names; and separate key words by semicolons) district heating and cooling; energy conservation; flow; standards; thermal metering; two-phase flow

13. AVAILABILITY

X. Unlimited

For Official Distribution. Do Not Release to NTIS

Order From Superintendent of Documents, U.S. Govemment Printing Office, Washington, D.C. 20402.

14. NO, OF

PRINTED PAGES

58

15. Price

X Order From National Technical Information Service (NTIS), Springfield,.VA. 22161

$\$ 11.95$ 

